OPEN ACCESS

Edited by:

Juan Aguirre,

Universidad de Chile, Chile

Reviewed by:

Marcello Trevisani,

University of Bologna, Italy

Javier Raso,

University of Zaragoza, Spain

*Correspondence:

Mercedes López

mmlopf@unileon.es

Specialty section:

This article was submitted to

Food Microbiology,

a section of the journal

Frontiers in Microbiology

Received: 22 October 2018

Accepted: 12 March 2019

Published: 02 April 2019

Citation:

López M, Calvo T, Prieto M,

Múgica-Vidal R, Muro-Fraguas I, Alba-Elías F and Alvarez-Ordóñez A

(2019) A Review on Non-thermal

Atmospheric Plasma for Food

Preservation: Mode of Action,

Determinants of Effectiveness, and Applications. Front. Microbiol. 10:622.

doi: 10.3389/fmicb.2019.00622

\section{A Review on Non-thermal Atmospheric Plasma for Food Preservation: Mode of Action, Determinants of Effectiveness, and Applications}

\author{
Mercedes López ${ }^{1,2 *}$, Tamara Calvo ${ }^{1}$, Miguel Prieto ${ }^{1,2}$, Rodolfo Múgica-Vidal ${ }^{3}$, \\ Ignacio Muro-Fraguas ${ }^{3}$, Fernando Alba-Elías ${ }^{3}$ and Avelino Alvarez-Ordóñez ${ }^{1,2}$ \\ ${ }^{1}$ Department of Food Hygiene and Technology, Universidad de León, León, Spain, ${ }^{2}$ Institute of Food Science and \\ Technology, Universidad de León, León, Spain, ${ }^{3}$ Department of Mechanical Engineering, Universidad de La Rioja, \\ Logroño, Spain
}

Non-thermal Atmospheric Plasma (NTAP) is a cutting-edge technology which has gained much attention during the last decade in the food-processing sector as a promising technology for food preservation and maintenance of food safety, with minimal impact on the quality attributes of foods, thanks to its effectiveness in microbial inactivation, including of pathogens, spoilage fungi and bacterial spores, simple design, ease of use, cost-effective operation, short treatment times, lack of toxic effects, and significant reduction of water consumption. This review article provides a general overview of the principles of operation and applications of NTAP in the agri-food sector. In particular, the numerous studies carried out in the last decade aimed at deciphering the influence of different environmental factors and processing parameters on the microbial inactivation attained are discussed. In addition, this review also considers some important studies aimed at elucidating the complex mechanism of microbial inactivation by NTAP. Finally, other potential applications of NTAP in the agri-food sector, apart from food decontamination, are briefly described, and some limitations for the immediate industrial implementation of NTAP are discussed (e.g., impact on the nutritional and sensory quality of treated foods; knowledge on the plasma components and reactive species responsible for the antimicrobial activity; possible toxicity of some of the chemical species generated; scale-up by designing fit-for-purpose equipment).

Keywords: plasma, food safety, food quality, microbial inactivation, food processing

\section{INTRODUCTION}

At present, consumers demand safe foods which also meet other quality criteria that traditional food preservation methods do not meet, such as convenience, high nutritional and sensorial quality, long shelf life, freshness, additives-free status, environment-friendly processing and low production costs (Fernández et al., 2012). Heat treatments have been widely used for many years to extend shelf life and enhance food safety and are generally well-accepted by consumers. However, they present certain drawbacks, such as the loss of nutrients and the considerable reduction in the 
organoleptic quality of some foods they cause (Jayasena et al., 2015). For this reason, a great deal of attention has been paid in recent years to the development of new preservation approaches, based on novel technologies, so-called "Emerging Food Preservation Technologies," whose objective is to inactivate microorganisms and enzymes without appreciably altering their nutritional, organoleptic and functional characteristics (Kim et al., 2014). These novel technologies include high hydrostatic pressures, pulsed electric fields, high-intensity ultrasounds, pulsed light, oscillating magnetic fields and, more recently, nonthermal atmospheric plasma (NTAP).

The term Plasma is used in Physics and Chemistry to designate the state of an ionized gas. Plasma is considered the fourth state of Matter. Although solid, liquid and gaseous states are more common on Earth due to their temperature and pressure conditions, they are, in global terms, exceptional, whereas plasma is the predominant state across the universe. It is estimated that up to $99 \%$ of Matter is found in this state, e.g., in auroras, the ionosphere, the solar wind, the sun and other stars (Lackmann and Bandow, 2014). In addition, it is also possible to artificially produce plasmas, and many of them are part of our daily lives (e.g., televisions or monitors with plasma screens, fluorescent tubes or neon lamps used in lighting and as indicators in equipment, etc.). They are also used for industrial purposes, e.g., to confer certain functional properties onto materials (paper, plastics, fabrics or electronic elements), to produce electrostatic precipitation of fine particles, to generate ozone, or as an active medium for chemical synthesis processes.

In order to produce plasma it is necessary to supply energy to a gas to cause its ionization. Plasmas can be classified according to their temperature into two large groups: thermal plasmas and cold plasmas (Lieberman and Lichtenberg, 2005). Thermal plasmas can reach temperatures of up to several thousand Celsius degrees and are used in applications where high temperatures are required, such as in casting processes in the metallurgical industry or in chemical synthesis processes (e.g., production of acetylene from natural gas). Cold plasmas, with temperatures close to ambient temperature, are on the contrary suitable for the treatment of heat sensitive materials.

These cold or non-thermal plasmas (NTAP) are generated by the application of an electric or electromagnetic field to a gas. The field energy causes the free electrons to accelerate and ionizes the gas atoms and molecules, which release more free electrons that in turn provoke new ionizations. In addition, excited electrons produce molecular dissociations, with the formation of new atoms and free radicals, also able to excite atoms and molecules to higher energy levels. Excited atoms and molecules, when returning to the more stable state, emit excess energy in the form of broad-spectrum electromagnetic radiation, including ultraviolet (UV) radiation. Consequently, the plasma is constituted basically by molecules and atoms in an excited state, positive and negative ions, free radicals, electrons, UV radiation and reactive oxygen and nitrogen species, such as ozone, superoxide, hydroxyl radicals, singlet oxygen, atomic oxygen, nitric oxide or nitrogen dioxide. Interestingly, all these agents show antimicrobial activity against a wide range of microorganisms, including bacteria, molds, yeasts, and even bacterial and fungal spores (Klämpfl et al., 2012; Tseng et al., 2012; Takamatsu et al., 2015; Dasan et al., 2016).

\section{POTENTIAL OF NTAP AS A PRESERVATION TECHNOLOGY IN THE FOOD INDUSTRY}

The possibility of using plasma as a surface decontamination technology was first pointed out in the late 60's in an American patent (Menashi, 1968). However, NTAP was not implemented yet in the food industry at that point, since cold plasmas could only be obtained under vacuum and at smallscale conditions, which was expensive and not applicable in industrial settings (Lackmann and Bandow, 2014). Nonetheless, the technological advances experienced at the late 90's in relation to the sources of plasma generation allowed the development of equipment capable of generating plasmas at atmospheric pressure, thus avoiding the need for vacuum cameras and pumps and facilitating continuous treatments with relatively simple and inexpensive equipment.

NTAP offers very important advantages for food industries, which makes it a very promising novel food preservation technology. Firstly, it allows short processing times. Indeed, it has been described that very short treatment times (between a few seconds and $2 \mathrm{~min}$ ) can cause more than 5 log reductions for different microorganisms, including pathogens such as Salmonella Typhimurium, S. Enteritidis, Escherichia coli, Staphylococcus aureus, Listeria monocytogenes, Campylobacter jejuni, Campylobacter coli, Aeromonas hydrophila, and even sporulated microorganisms such as Bacillus cereus and Clostridium botulinum (Deng et al., 2007; Muranyi et al., 2007; Rowan et al., 2007; Song et al., 2009; Shi et al., 2011; Lee et al., 2012b; Jahid et al., 2014; Ziuzina et al., 2014). In addition, it is effective at room temperature, which makes it particularly interesting for heat-sensitive products, and can be used to treat pre-packaged foods (Fröhling et al., 2012a; Rød et al., 2012; Ziuzina et al., 2014; Jayasena et al., 2015), which prevents their subsequent recontamination. Finally, its non-toxic nature and the reduced consumption of water and chemical agents result in a significant reduction of effluents, which is beneficial not only from an economic but also from an environmental point of view.

This set of advantages has led in recent years to explore the use of NTAP for food preservation, and there are already numerous studies, focused on characterizing its antimicrobial effectiveness and on deciphering the inactivation mechanisms involved. Nevertheless, a great research effort is still necessary to accomplish its successful implementation at industrial level as a safe and effective alternative to traditional preservation methods, with the main challenges arising from the difficulty in interpreting the data obtained by different research groups which use very diverse equipment and operating conditions, resulting in very different plasmas in terms of properties and, consequently, with very different antimicrobial effectiveness. However, some general conclusions can be drawn on various aspects related to the mechanisms of microbial inactivation by NTAP and the 
factors that determine its lethal efficacy, which will be discussed in the following sections of this review article.

\section{MECHANISMS OF MICROBIAL INACTIVATION BY NTAP}

Although several studies have tried to elucidate the mode of microbial inactivation by various plasmas obtained under atmospheric conditions, the specific mechanisms leading to microbial death are not precisely known yet.

It is well-known that UV radiation with wavelengths in the $220-280 \mathrm{~nm}$ range is capable of inhibiting microbial growth by inducing the formation of DNA thymine dimers. Indeed, UV light has been used for years for the decontamination of water, air and surfaces. However, the contribution of UV radiation to the antimicrobial effect of plasmas obtained at atmospheric pressure is controversial. Thus, although some researchers hypothesize that UV-C radiation present in plasma plays an important inactivating role (Boudam et al., 2006; Eto et al., 2008; Muranyi et al., 2010), most authors (Laroussi and Leipold, 2004; Deng et al., 2006; Lee et al., 2006; Dobrynin et al., 2009, 2011; Joshi et al., 2011; Miao and Yun, 2011; Reineke et al., 2015) believe that UV radiations are not generated at the most effective wavelengths or are absorbed by the gas molecules themselves (Reineke et al., 2015) and, therefore, are not involved in microbial inactivation (Patil et al., 2014; Surowsky et al., 2014). Indeed, Reineke et al. (2015) compared the effectiveness of different plasmas for the inactivation of Bacillus atrophaeus and Bacillus subtilis spores and found that, although plasmas containing oxygen and nitrogen emitted four times more UV radiation than pure argon plasmas, the greatest lethal effect was achieved when pure argon was used as the working gas. These authors suggested that the antimicrobial effect was determined by reactive species of oxygen and nitrogen generated in the pure gas, and especially by hydroxyl radicals. Other authors have also tested the contribution of UV light by exposing E. coli cells (Liu et al., 2008; Gweon et al., 2009) and Bacillus cereus (van Bokhorst-van de Veen et al., 2015) and B. subtilis spores (Hong et al., 2009) to the action of plasma by intercalating between the plasma generation point and the treatment medium a lithium fluoride filter or a fused silica quartz plate transparent to UV light, which allows cell/spore exposure to the radiation potentially emitted by the plasma source but avoids contact with chemical reactive species. These studies demonstrated that the contribution of UV light to microbial inactivation was negligible, compared to that observed for direct exposition to plasma. In addition, exposure of $B$. cereus vegetative cells to nitrogen plasma has been shown to result in a transcriptional response in which the expression of genes involved in UV damage repair ( $u v r A, u v r B)$ was unaffected, while various genes involved in the response to oxidative stress, such as those encoding nitric oxide dioxygenase, as well as membraneassociated enzymes that catalyze oxidation-reduction reactions, were overexpressed (Mols et al., 2013). Finally, it has also been shown that microorganisms exhibiting variability in resistance to UV light exhibit a similar tolerance against NTAP. For instance, although $B$. cereus spores were more sensitive to UV light than spores of Geobacillus stearothermophilus and B. atrophaeus, a given NTAP treatment produced a similar degree of inactivation for the three species (van Bokhorst-van de Veen et al., 2015), suggesting that the mechanism of inactivation through both technologies was different.

There exists on the contrary a general agreement in that reactive chemical species generated through gas ionization exert an antimicrobial effect through a direct and non-specific attack on various microbial structures and components, including cellular envelopes, DNA and proteins (Song et al., 2009; Colagar et al., 2010; Surowsky et al., 2014; Yost and Joshi, 2015).

\section{Lesions at the Cellular Envelopes}

Various authors (Dobrynin et al., 2009; Muranyi et al., 2010; Miao and Yun, 2011; Tseng et al., 2012; Tian et al., 2015) have identified the mechanical or oxidative damage caused to cellular envelopes as the main cause of death after NTAP treatments. The mechanical erosion of cellular envelopes could be due either to the impact of plasma energy particles, such as electrons and excited atoms (Butscher et al., 2016), or to the accumulation of charges in certain parts of the cell surface, which would lead to its permeabilization through the formation of pores, in a phenomenon known as electroporation (Laroussi et al., 2003). Moreover, damage at this level would facilitate the release of important intracellular components and the invasion of reactive species which would attack other cellular components, such as DNA and proteins, thus accelerating the inactivation process. In addition to this mechanical effect, neutral reactive species generated in plasma, such as atomic oxygen, hydroxyl and peroxyl radicals, metastable oxygen or ozone, are capable of causing oxidative damage to various cellular structures and macromolecules. If this damage is very intense and exceeds the physiological repair capacity, it will lead to microbial death (Leipold et al., 2010). In fact, the use of substances that chelate reactive species has been shown to reduce the antimicrobial efficacy of NTAP. Thus, several sequestering agents of various reactive oxygen species, such as catalase, superoxide dismutase, dimethyl sulfoxide, thiourea, sodium azide, and various antioxidants (glutathione, ascorbic acid, sodium pyruvate, mannitol, histidine, or tocopherol) have been reported to protect microorganisms, such as E. coli (Joshi et al., 2011; Yost and Joshi, 2015) or P. aeruginosa (Takamatsu et al., 2015), from the action of NTAP. Yost and Joshi (2015) showed that previous incubation of E. coli with catalase provided a greater protective effect than vitamin $\mathrm{E}$ and thiourea, concluding that peroxides such as $\mathrm{H}_{2} \mathrm{O}_{2}$ could be the major chemical species responsible for microbial inactivation by NTAP. On the other hand, Takamatsu et al. (2015) observed that the presence of dimethyl sulfoxide or sodium azide resulted in lower $P$. aeruginosa inactivation rates than those observed when catalase or superoxide dismutase were used, suggesting that hydroxyl radicals and singlet oxygen were the main agents involved in microbial inactivation.

Reactive species exert their oxidative effect especially on the polyunsaturated fatty acids of the cytoplasmic membrane (Laroussi and Leipold, 2004), which are very susceptible to lipid peroxidation phenomena. Lipid peroxidation can compromise 
cell viability by modifying membrane properties, decreasing its permeability and even its integrity (Joshi et al., 2011; Hosseinzadeh Colagar et al., 2013). Lipid peroxidation is a chain reaction that begins with the attack of unsaturated fatty acids by reactive oxygen species (or any reactive species), which extract a hydrogen atom from a methylene group (-CH2), giving rise to the formation of a lipid radical $\left(L^{*}\right)$ which can react rapidly with an oxygen molecule to give a peroxyl radical (LOO*). These radicals can extract new hydrogen atoms from other lipids and become hydroperoxides $(\mathrm{LOOH})$, which undergo chemical degradative phenomena to produce very toxic degradation compounds, such as alkoxy $\left(\mathrm{LO}^{*}\right)$, peroxyl and hydroxyl radicals and reactive aldehydes, including malondialdehyde and 4-hydroxynonenal. In fact, malondialdehyde is commonly used as a biological marker of oxidative stress (Liu et al., 2008), and a linear correlation between the content of this compound in E. coli, the time of exposure to NTAP and microbial viability has been described (Joshi et al., 2011; Hosseinzadeh Colagar et al., 2013; Yost and Joshi, 2015). These intermediate reactive compounds also behave as secondary toxic messengers of the reactive species generated in the plasma, amplifying their lethal damage to the cell (Joshi et al., 2011). Furthermore, many have greater stability than the plasma reactive species and, consequently, a much longer cytotoxic action, and can disseminate from the membrane toward more distant molecules, like DNA (Yost and Joshi, 2015), where they exert their action by interacting with nucleotides, inducing important modifications and crosslinks and making cell growth and DNA repair more difficult (del Rio et al., 2005). In S. Typhimurium, malondialdehyde has been shown to be capable of inducing base insertions, deletions and substitutions, thus potentially contributing to significant DNA alterations (Dobrynin et al., 2009). In addition, some of the aldehydes generated in the peroxidation process, including malondialdehyde, are capable of forming cross-links in the polypeptide chains of proteins, affecting the activity of enzymes and membrane-associated proteins. To sum up, NTAP causes an uncontrolled process of lipid peroxidation which results in (i) changes in the membrane chemical composition, ultrastructural organization and permeability, (ii) a decrease in membrane fluidity, and (iii) the inactivation of membraneassociated enzymes, thereby compromising cellular viability.

The existence of damages in the cellular envelopes upon exposure to NTAP has been repeatedly demonstrated by using direct and indirect methods. Micrographs obtained through scanning electron microscopy for both vegetative cells (Staphylococcus aureus, E. coli, B. subtilis, Campylobacter jejuni, Citrobacter freundii, Pseudomonas aeruginosa, Enterococcus faecalis, Saccharomyces cerevisiae, Candida albicans) and bacterial (B. cereus, B. subtilis and G. stearothermophilus) and fungal (Aspergillus parasiticus, Aspergillus flavus) spores have allowed the identification of morphological alterations, such as size reductions, changes of shape, surface structure modifications, presence of pores in membranes and envelope disruptions (Yu et al., 2006; Hong et al., 2009; Miao and Jierong, 2009; Joshi et al., 2011; Miao and Yun, 2011; Bermúdez-Aguirre et al., 2013; Ryu et al., 2013; Zhang et al., 2013; Kim et al., 2014; Surowsky et al., 2014; Ma et al., 2015; van Bokhorst-van de Veen et al., 2015; Butscher et al., 2016; Cui et al., 2016a; Dasan et al., 2016; Gabriel et al., 2016b; Lai et al., 2016; Nishime et al., 2017). For bacterial spores, a loss of refringence, not accompanied by the onset of germination, has been observed for $B$. cereus by phase contrast microscopy (van Bokhorst-van de Veen et al., 2015). Damages in the cell envelopes have also been evidenced indirectly by determining the release of different intracellular components, including small ions such as $\mathrm{K}^{+}$(Zhang et al., 2013), ATP (Cui et al., 2016a), nucleic acids (Zhang et al., 2013; Tian et al., 2015; Cui et al., 2016a), proteins (Liu et al., 2008; Miao and Jierong, 2009; Miao and Yun, 2011; Zhang et al., 2013; Tian et al., 2015; Cui et al., 2016a) or dipicolinic acid in the case of bacterial spores (Tseng et al., 2012), or by monitoring the entry into the cell of fluorescent dyes which cannot cross intact membranes, such as propidium iodide (Joshi et al., 2011; Surowsky et al., 2014; Ma et al., 2015; Tian et al., 2015), the decrease in membrane potential or its depolarization (Joshi et al., 2011; Surowsky et al., 2014; Tian et al., 2015; Yost and Joshi, 2015), as well as the inability of cells to retain the Gram staining (Muranyi et al., 2010; Joshi et al., 2011).

\section{Damages at Intracellular Level}

However, it appears that microbial cell envelopes are not the only damaged cell structure. Indeed, reactive species, such as singlet oxygen, hydrogen peroxide, nitric oxide and excited atoms and molecules, can rapidly and easily diffuse into the cells, even when the membrane is intact, and oxidize many macromolecules (Dobrynin et al., 2011; Joshi et al., 2011; Yost and Joshi, 2015). Recently, Ziuzina et al. (2015b) detected and quantified, in L. monocytogenes and E. coli, the intracellular pool of reactive oxygen species after exposure to NTAP, using fluorescence techniques. They observed an increase in their concentration after NTAP treatment, which was more pronounced in L. monocytogenes. Similarly, Joshi et al. (2011), using highly selective fluorescent compounds for singlet oxygen and hydrogen peroxide quantification, found that the singlet oxygen concentration inside E. coli cells increased steadily within a 60 second NTAP treatment, whereas hydrogen peroxide content reached a maximum value after $12 \mathrm{~s}$ of treatment. In S. cerevisiae, an increase in the intracellular concentration of reactive species of oxygen and, especially, of nitric oxide has also been reported (Ryu et al., 2013). Once inside the cell, reactive substances provoke damage not only on lipids, but also on proteins, nucleic acids and carbohydrates. In order to neutralize the deleterious effects of such oxidant species or to repair the damage they cause, microorganisms have a number of mechanisms of elimination and transformation of these compounds, such as catalases, superoxide dismutases and glutathione and thioredoxin systems, among others. Nevertheless, when the accumulation of reactive oxygen species exceeds the cellular detoxifying capacity, and their concentration surpasses a critical level, the microbial cell suffers from oxidative stress, which induces the expression of certain genes and the activation of different defense responses (Pomposiello and Demple, 2002). For instance, in E. coli, the regulators oxyRS and soxRS are involved in the cellular response to oxidative stress induced by NTAP. Indeed, the exposure of $E$. 
coli to NTAP results in the overexpression of the oxyS, soxS, and soxR genes, as well as of those genes encoding for the catalase (KatG) and superoxide dismutase (SodA) enzymes (Sharma et al., 2009; Yost and Joshi, 2015). In addition, E. coli mutants lacking the $\operatorname{oxyR}$ or soxS genes have been shown to be more susceptible than wild-type strains to a plasma treatment using as working gases helium or a mixture of helium and oxygen (Perni et al., 2007). Similarly, Yost and Joshi (2015) reported that strains deficient in superoxide dismutase (SodA) were more rapidly inactivated by a NTAP treatment than wild-type strains. Overall, these results demonstrate the occurrence of reactive oxygen species within the cells during plasma treatments and suggest that the membrane is not the unique cellular component targeted by NTAP.

At the intracellular level, reactive species of oxygen and nitrogen, such as atomic oxygen, hydroxyl radicals $\left(\mathrm{OH}^{*}\right)$, hydroperoxyls $\left(\mathrm{HOO}^{*}\right)$, superoxides $\left(\mathrm{O}_{2}{ }^{*}\right)$ and nitric oxide (NO), are capable of interacting with various macromolecules and, according to some authors (Yost and Joshi, 2015), DNA and proteins are especially susceptible.

\section{DNA Damage}

Damage to DNA is caused through the oxidation of bases. For example, oxidation of guanine generates 8-hydroxy2'deoxyguanosine (OHdG), a compound which is used as a marker of oxidative DNA damage (Joshi et al., 2011; Yost and Joshi, 2015). The oxidation of DNA bases leads to a transversion (substitution of a purine for a pyrimidine or vice versa), which alters the bonds between DNA bases, causing changes in DNA conformation, and frequently leading to errors in the reading of the strand, mutagenesis and cell death. Some of the chemical species of plasma also react with deoxyribose carbons, breaking the N-glucosidic bond, thus generating apurinic or apyrimidine sites (abasic sites). All these changes may eventually lead to DNA strand ruptures (Hosseinzadeh Colagar et al., 2013; Ryu et al., 2013; Yost and Joshi, 2015). Microorganisms can nevertheless respond to DNA damage inflicted by NTAP. Indeed, transcriptional studies using microarrays have demonstrated that up to 18 genes involved in the SOS response are overexpressed upon exposure to NTAP (Sharma et al., 2009). Such overexpression is triggered when the level of accumulated damage is so high that microbial replication mechanisms are blocked. Similarly, Sharma et al. (2009), studying the transcriptomic response of $E$. coli cells exposed for 2 min to an argon plasma, observed an intense overexpression of several genes encoding for polymerase enzymes involved in the repair of extremely damaged DNA ( $p o l B, \operatorname{din} B, u m u C$, and $u m u D)$. In addition, these authors also detected an incomplete induction of some more specific DNA repair mechanisms, such as the nucleotide cleavage repair system, and concluded that plasma exerted massive damage at DNA level. The existence of significant damage to microbial DNA has also been corroborated using agarose gel electrophoresis techniques (Joshi et al., 2011; Han et al., 2013; Hosseinzadeh Colagar et al., 2013; Ryu et al., 2013). For instance, Joshi et al. (2011) observed fragmentation of $E$. coli DNA after NTAP treatment, which increased with increasing treatment times, and Hosseinzadeh Colagar et al. (2013) found that treatment times longer than 3 min resulted in a complete degradation of E. coli genomic DNA. Similar results have been obtained for Saccharomyces cerevisiae by Ryu et al. (2013), who also found complete DNA fragmentation after exposure to plasma for up to $3 \mathrm{~min}$, and by Muranyi et al. (2010), who detected massive DNA damage in $B$. subtilis vegetative cells and, to a lesser extent, in their sporulated forms.

\section{Damage to Proteins}

According to some authors, proteins and cytoplasmic enzymes would also suffer damage during plasma treatments. Indeed, reactive species are able to (i) break peptide bonds, (ii) oxidize amino acid side chains, especially of sulfur amino acids, such as methionine and cysteine, and amino acids harboring aromatic rings (tryptophan, phenylalanine and tyrosine), (iii) produce crosslinks within proteins, and (iv) give rise to aggregation phenomena, which are favored by the formation of intraand inter-molecular disulfide bonds. All these effects result in modifications in the conformation and three-dimensional structure of proteins and enzymes (Surowsky et al., 2013). In addition, in the case of enzymes, their activity could also be compromised by the oxidation of their cofactors (Colagar et al., 2010). Actually, the oxidation of just one amino acid in a protein can affect its function (Lackmann et al., 2013). These latter authors showed that the loss of 3-phosphate glyceraldehyde activity after NTAP treatment was due to the oxidation of a cysteine residue (cys150) of its active site, which is known to be irreversible (Brandes et al., 2009). However, it is still unknown which enzymes and proteins are specific targets for the action of NTAP. In the particular case of vegetative cells, Hosseinzadeh Colagar et al. (2013) analyzed E. coli proteins after exposure to plasma using sodium dodecyl sulfate polyacrylamide gel electrophoresis (SDS-PAGE) techniques and found that high molecular weight proteins, of between 50 and $90 \mathrm{KDa}$, were especially sensitive to NTAP, observing a decrease in their content as treatment time increased. In addition, these authors also observed that the concentration of free amino acids linearly increased with exposure time, which suggested that NTAP is not only able to break peptide bonds, but also to fragment proteins liberating free amino acids. Concerning bacterial spores, several authors (Klämpfl et al., 2012; Tseng et al., 2012) have pointed out that the effectiveness of NTAP against these resistant forms is due to the inactivation of various enzymes responsible for spore germination, such as GerA and GerB, as well as to the inactivation of channel proteins involved in the transport of ions and dipicolinic acid, which also results in the inability to initiate germination processes.

\section{Indirect Mechanism of Action}

Finally, apart from the direct effects caused by reactive species present in plasmas, an indirect mechanism of action, through the formation of other cytotoxic compounds, has been also described. Thus, Yost and Joshi (2015) showed that hydroxyl radicals $\left(\mathrm{OH}^{*}\right)$ can be generated from $\mathrm{H}_{2} \mathrm{O}_{2}$ and superoxide radicals $\left(\mathrm{O}_{2-}^{*}\right)$ in the presence of transition metals such as iron or copper. Although $\mathrm{OH}^{*}$ radicals can be produced by different routes, the Haber-Weiss reaction is the most habitual (Lemire 
et al., 2013). This reaction consists in the transformation of the ferric cation to ferrous cation $\left(\mathrm{Fe}^{3+}+\mathrm{O}_{2}^{-*} \rightarrow \mathrm{Fe}^{2+}+\right.$ $\mathrm{O}_{2}$ ) by the superoxide radical. Afterwards, the ferrous cation reacts with $\mathrm{H}_{2} \mathrm{O}_{2}$ to produce $\mathrm{Fe}^{3+}$, hydroxyl anions and hydroxyl radicals, which also exert and antimicrobial activity. Nitric oxide (NO) can also react with oxygen or superoxide radicals to form nitrogen dioxide $\left(\mathrm{NO}_{2}\right)$, peroxynitrites $\left(\mathrm{ONOO}^{-}\right.$or $\left.\mathrm{ONO}_{2}^{-}\right)$and nitrous anhydride $\left(\mathrm{N}_{2} \mathrm{O}_{3}\right)$ (Han et al., 2013), which all have a broad spectrum of antimicrobial activity, although they differ in reactivity, stability and biological activity (Fang, 2004).

\section{FACTORS DETERMINING THE ANTIMICROBIAL EFFECTIVENESS OF NTAP}

There are several factors known to influence the microbial inactivation achieved through NTAP treatments. Some of these factors are related to the conditions used for plasma generation and application, while others are associated with the particular properties of the microorganism targeted or with the characteristics of the treatment medium or food. The following sections of this review article will compile and discuss the information available in the literature in relation to these aspects.

\section{Processing Parameters}

NTAP may be obtained through electrical discharges, which may be accomplished by using very diverse systems, e.g., corona discharge, micro hollow cathode discharge, atmospheric pressure plasma jet, gliding arc discharge, dielectric barrier discharge (DBD), radiofrequency (rf) and microwaves. In any case, electrical discharges are initiated and sustained through electron collision processes under the action of specific electric or electromagnetic fields. Among all the existing plasma sources, DBD and plasma jets are the most widely explored configurations in food research, due to their easiness of construction and adoption. Indeed, there are some commercially available DBD and plasma jet configurations. Nevertheless, regardless of the equipment used, the molecular composition of plasma will depend on the energy supplied, which in turn is determined by voltage, power and excitation frequency, and even on the composition and flow rate of the working gas, with these parameters being very variable among different NTAP units, which makes it very difficult to carry out direct comparisons among research studies executed employing different equipment and NTAP processing conditions. However, it is possible to draw some general conclusions on how some processing parameters affect the level of microbial inactivation achieved through NTAP treatments.

With processing times described in the literature ranging from a few seconds up to several minutes, it is well-known that microbial inactivation increases with processing time, although not in all cases exponentially. Thus, a wide variety of inactivation kinetics are observed in the published data, where it is frequent to find both linear, concave-upward (tailing) and concave-downward (shoulders) kinetics (Lee et al., 2011; Calvo et al., 2016, 2017).
Voltage (difference of potential between two points per unit of charge, expressed in Volts), power (electrical energy consumed per unit of time, expressed in Watts) and frequency (number of cycles per second, expressed in Hertz) have a great effect on the antimicrobial effectiveness of NTAP, as they are known to determine the input energy and, consequently, the chemical reactive species generated and their concentration. It has been repeatedly demonstrated that an increase in voltage increases microbial inactivation of both vegetative cells and bacterial spores (Table 1). In fact, Liu et al. (2013) have found, after using different voltages to generate helium plasmas, that the content of reactive chemical species and, in particular, of $\mathrm{N}_{2}^{+}, \mathrm{OH}, \mathrm{He}$ and $\mathrm{O}$, and the level of inactivation achieved for $S$. aureus, increased with the voltage applied. It has also been shown that, working under a constant voltage, an increase in excitation frequency or in power gives rise to greater lethal effects in a wide range of microbial species (Table 1). Taking these findings into account it would be advisable to use high voltages, power, and frequencies for the generation of plasmas. However, some technological constraints, including high costs, and potential negative impacts on food quality, due to an excessive temperature rise, represent a limit toward the use of extreme processing conditions in industrial practice (Kim et al., 2011; Alkawareek et al., 2012; Daeschlein et al., 2012; Butscher et al., 2016).

Another variable to take into account when considering the antimicrobial effectiveness of NTAP treatments is the working gas used. A wide variety of gases have been used to generate plasma, with the most frequent ones being nitrogen, oxygen, carbon dioxide, argon, helium, air, or mixtures of some of these gases (Table 1). All of them give rise to plasmas capable of achieving certain level of microbial inactivation, and there is no general agreement on which one is the most effective gas. Lee et al. (2011) compared the effectiveness against $L$. monocytogenes of plasmas obtained with helium or nitrogen and observed a higher inactivation level for nitrogen-based plasmas. Other studies have described that air-based plasmas are most effective in inactivating E. coli O157:H7, B. cereus, S. aureus, L. monocytogenes, L. innocua and various serovars of Salmonella enterica, such as $S$. Anatum, S. Stanley, S. Typhimurium and $S$. Enteritidis, than plasmas generated with nitrogen (Marsili et al., 2002; Niemira, 2012; Calvo et al., 2016, 2017). On the contrary, Takamatsu et al. (2015) obtained a greater lethal effect against $S$. aureus and $P$. aeruginosa with nitrogen and $\mathrm{CO}_{2}$ based plasmas than with plasmas generated with air, $\mathrm{O}_{2}$ or argon, and Rowan et al. (2007) concluded that oxygen is the gas of choice, over $\mathrm{CO}_{2}$ or nitrogen, when generating plasmas for the inactivation of E. coli, C. jejuni, C. coli, L. monocytogenes, S. Typhimurium, $S$. Enteritidis and B. cereus spores. On the other hand, it seems to exist an agreement, although with some exceptions (Reineke et al., 2015), in that the addition of small amounts of oxygen to noble gases, such as helium (Gweon et al., 2009; Kim et al., 2011, 2013; Lee et al., 2011, 2012a; Galvin et al., 2013) and argon (Surowsky et al., 2014), or nitrogen (Lee et al., 2011, $2012 \mathrm{~b}$ ) improves the antimicrobial effectiveness of NTAP against vegetative cells and spore-forming bacteria (Table 1). This effect is mainly attributed to a higher formation of reactive oxygen species, such as hydroxyl and hydroperoxyl radicals, atomic 


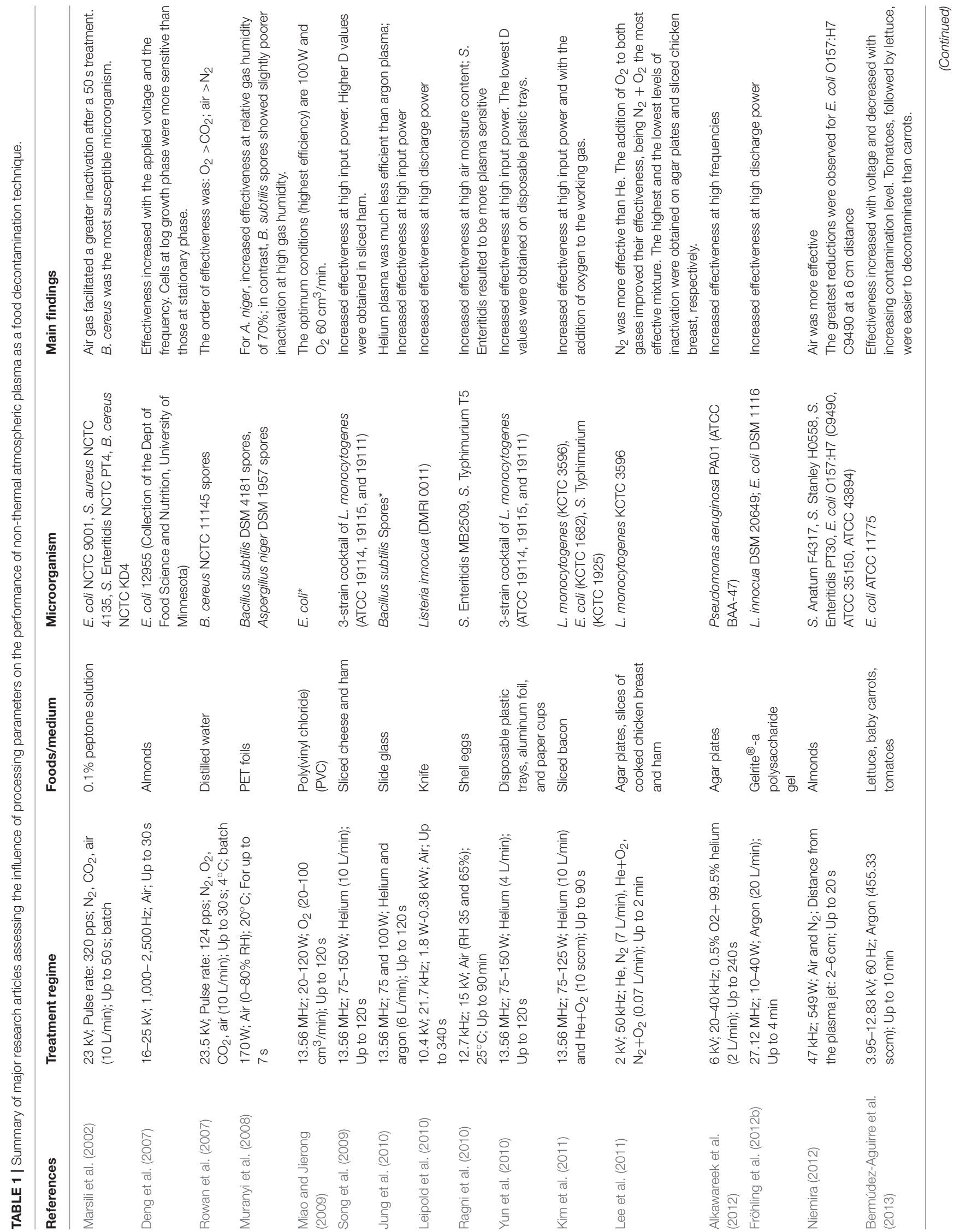




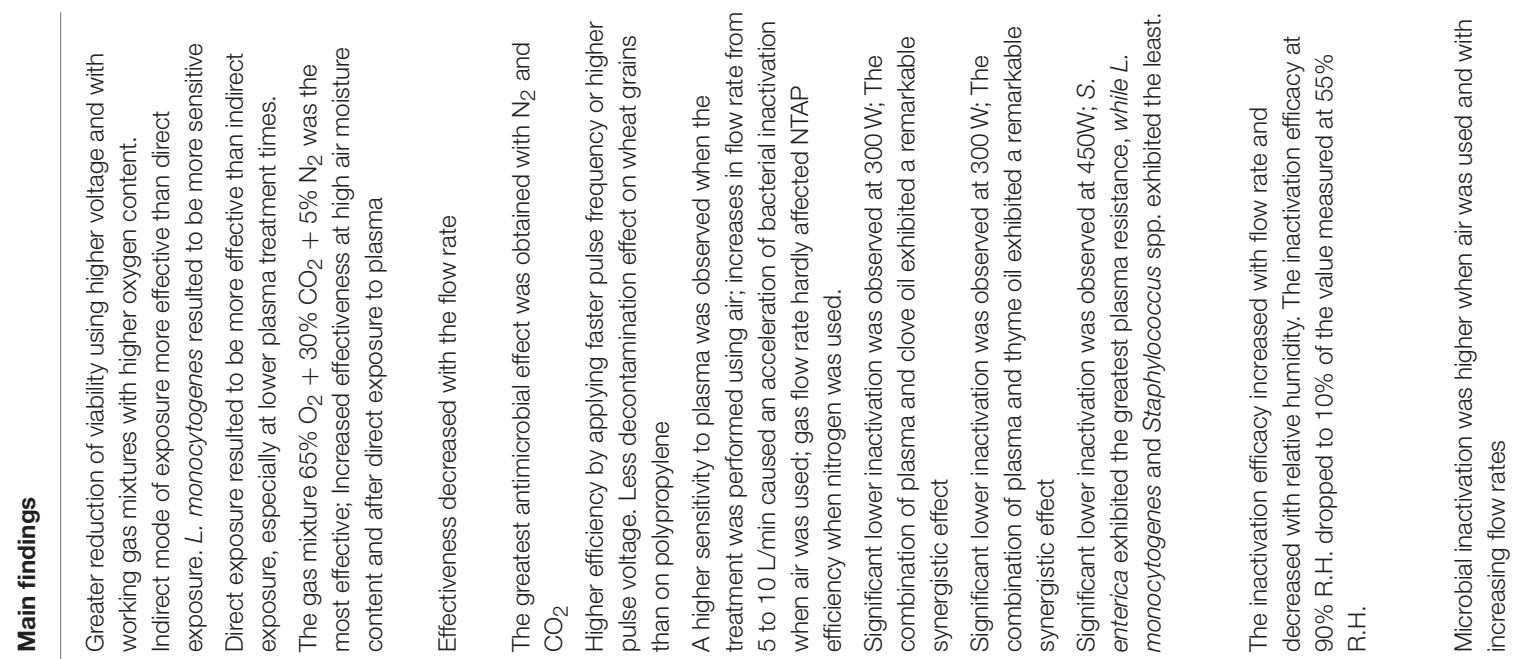

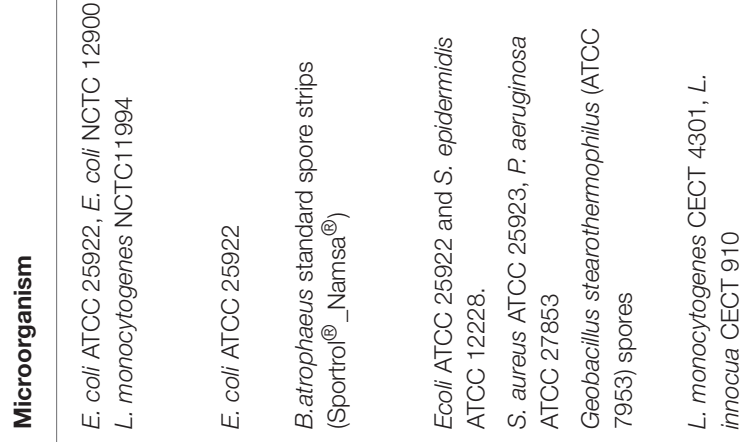

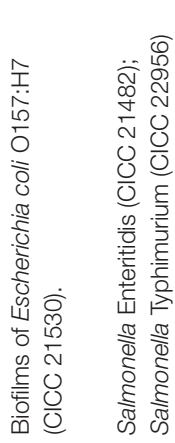

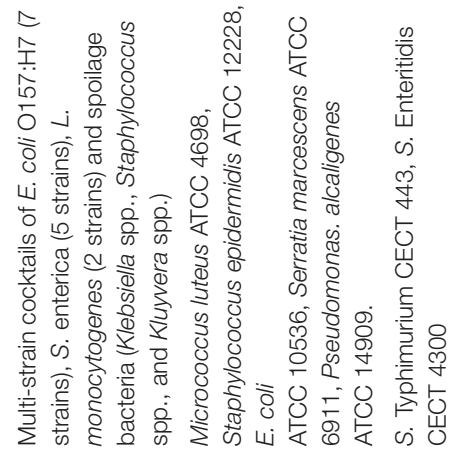

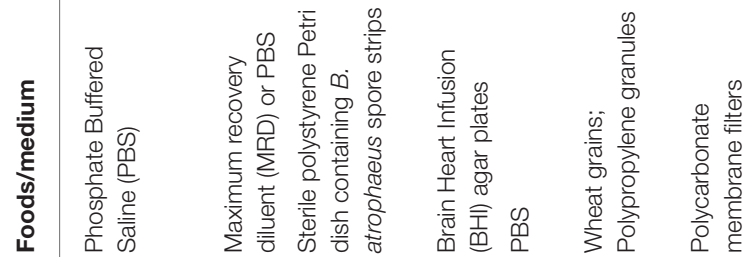
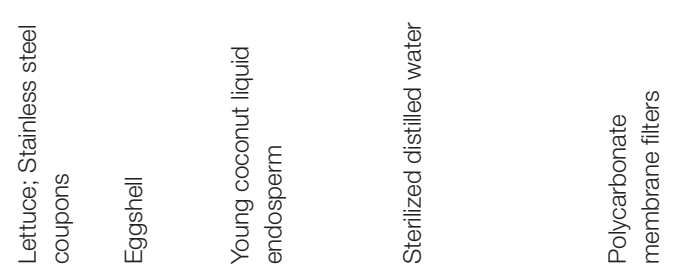

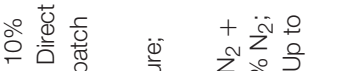

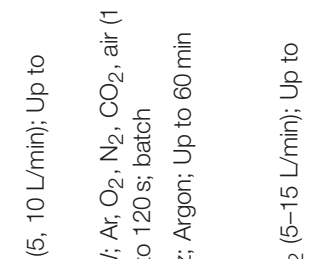

๕)

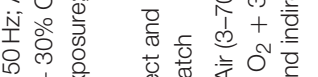

बٓ

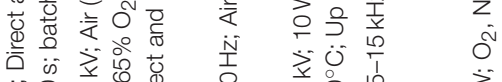

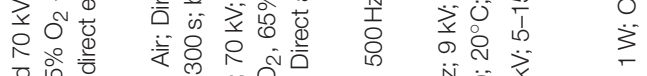

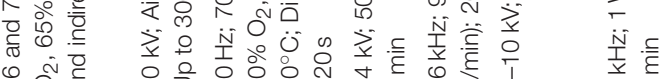

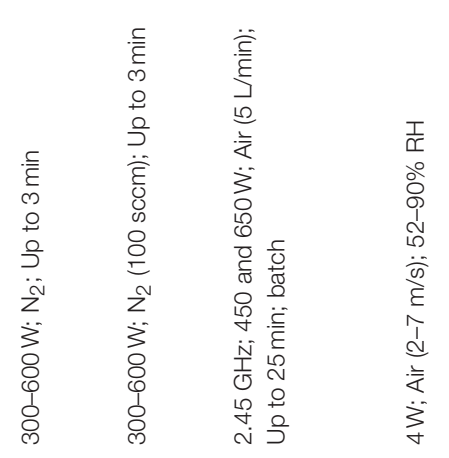

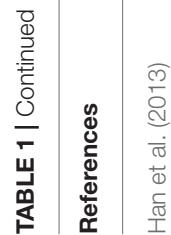
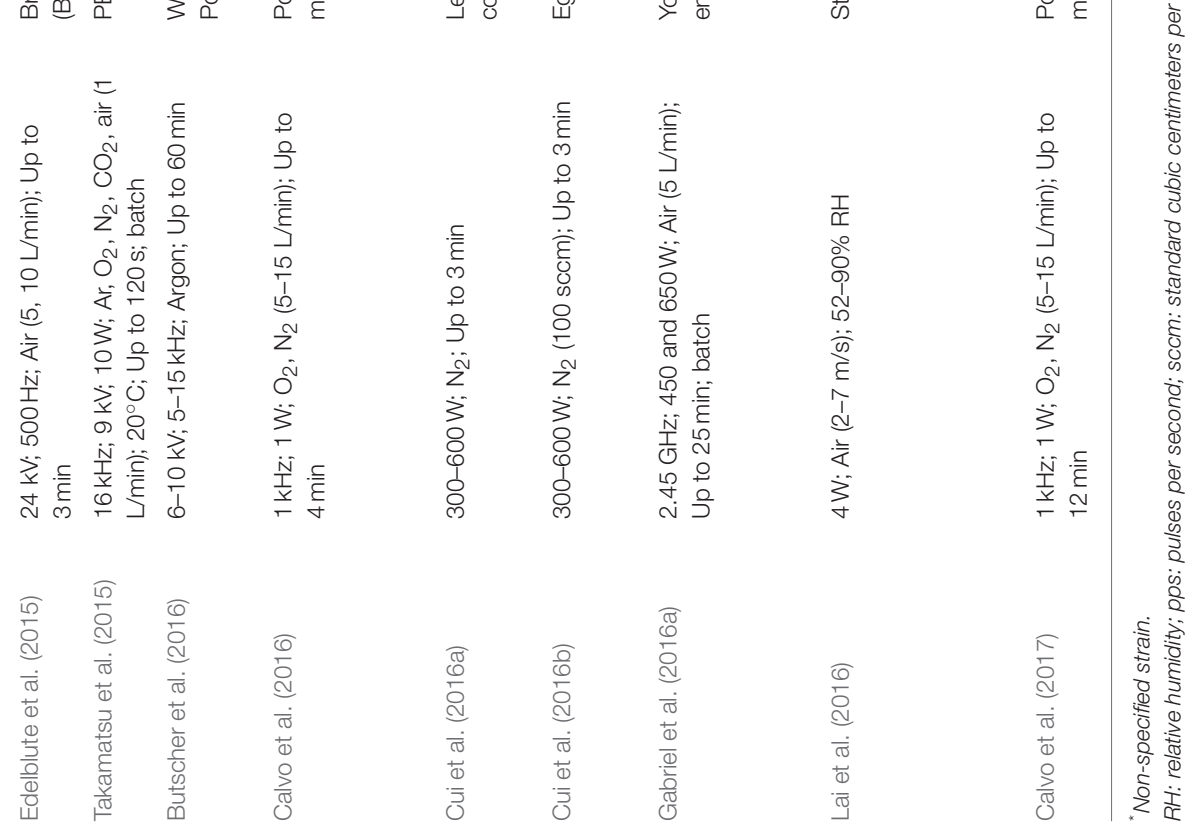
oxygen, hydrogen peroxide, singlet oxygen and ozone, all of them with a high antibacterial activity.

Another processing parameter determining the antimicrobial effectiveness of NTAP is the gas moisture content. In fact, it has been occasionally observed (Dobrynin et al., 2011) that the use of completely dry gases is ineffective for E. coli inactivation, and there are several studies which show that an increase in the water content of the gas improves its effectiveness (Table 1). Thus, Ragni et al. (2010) reported that an increase in the air relative humidity from 35 to $65 \%$ increased the inactivation of $S$. Enteritidis and $S$. Typhimurium from 2.5 to $4.5 \log$ cycles, and attributed this effect to a higher concentration of hydroxyl radicals in the plasma. Similar results were found by Patil et al. (2014) for B. atrophaeus spores. These authors used plasmas with different moisture content $(3,10,30,50$, and $70 \%)$, and obtained a 5 to $6 \log$ reduction at humidities of 3 and $10 \%$, while a complete inactivation was observed at higher humidities. These authors related this higher antimicrobial activity to the increased generation of numerous reactive species, such as $\mathrm{N}_{2} \mathrm{O}_{5}, \mathrm{H}_{2} \mathrm{O}_{2}, \mathrm{HNO}_{4}$, or hydroxyl radicals, and, especially, to the decomposition of ozone in the presence of water, with the consequent formation of highly oxidizing species, such as hydroxyl and hydroperoxyl radicals, superoxide anion and $\mathrm{H}_{2} \mathrm{O}_{2}$. On the contrary, a recent study by Lai et al. (2016) has shown that when the relative air humidity increased from 52 to $81 \%$ or from 62 to $81 \%$, the inactivation efficiency of NTAP against E. coli and Staphylococcus epidermidis decreased by 87 and 58\%, respectively, which was linked to a decrease in the concentration of negative ions in plasma. These apparently contradictory results could be explained by the existence of an optimum moisture value for achieving a maximum antimicrobial activity. For instance, in the particular case of Aspergillus niger, a progressive increase in microbial inactivation was observed up to a moisture content of $70 \%$, which was the optimum moisture content for NTAP generation (Muranyi et al., 2008).

Gas flow rate also seems to influence the effectiveness of NTAP treatments (Table 1). Lai et al. (2016) reported a steady increase in E. coli, S. epidermidis and P. alcaligenes inactivation when air flow rates increased from 2 to 7 meters/s, linked to a linear rise in the concentration of negative ions in the generated plasma. Results from our research group have demonstrated that the effect of gas flow rate on L. monocytogenes and L. innocua inactivation through NTAP depended on the type of gas used to generate plasma. Indeed, increases in flow rate from 5 to $10 \mathrm{~L} / \mathrm{min}$ caused an acceleration of bacterial inactivation when air was used, while an additional increase of gas flow from 10 to $15 \mathrm{~L} / \mathrm{min}$ had a minor impact on microbial inactivation. On the other hand, gas flow rate hardly affected NTAP treatment efficiency when nitrogen was used to generate plasma (Calvo et al., 2016). A similar behavior was also observed for $S$. Enteritidis and $S$. Typhimurium (Calvo et al., 2017). In contrast, Edelblute et al. (2015) found that an increase in air flow rate from 5 to 10 liters per minute was accompanied by a loss of efficacy of NTAP for the inactivation of E. coli and S. epidermidis, and attributed this effect to a reduction in ozone and $\mathrm{NO}_{2}$ concentration. Moreover, Miao and Jierong (2009), using oxygen as working gas, suggested the existence of an optimal flow rate for the inactivation of $E$. coli, reporting that, once this optimal flow rate is surpassed, the lethal effect achieved is reduced. According to these authors, at low flow rates, the number of reactive species, mainly constituted by oxygen radicals, is lower than at high flow rates, but they have a higher average energy and, therefore, the likelihood of each one colliding with microbial cells increases and, consequently, also their antimicrobial effectiveness. However, at higher flow rates the number of reactive species will be higher, but they will have a lower average energy, and their antimicrobial action would be comparatively lower.

NTAP effectiveness can also depend on whether treatments are carried out directly or indirectly. In direct treatments, the product is physically located in the field where plasma is generated, and, therefore, it is in intimate contact with all the photons and chemical species produced. In contrast, in indirect treatments plasma is produced at some distance from the product, and is usually displaced toward it, using a rapid flow of the feed gas. In principle, one would expect that indirect treatments would be less effective in microbial inactivation. Patil et al. (2014) demonstrated that the direct exposure of $B$. atrophaeus spores to plasmas generated with gases of different composition (air; a mixture of nitrogen [90\%] and oxygen [10\%]; a mixture of oxygen [65\%], $\mathrm{CO}_{2}[30 \%]$, and nitrogen [5\%]) caused the inactivation of at least $6 \log$ cycles, whereas for indirect exposures inactivation rates ranged from 2.1 to $6.3 \mathrm{log}$ units, depending on the type of gas used. Nevertheless, other authors have obtained conflicting results. Thus, Han et al. (2013) found that indirect treatments were more effective against $E$. coli and L. monocytogenes than direct treatments, and suggested that this fact could be due to the recombination of reactive radicals with a short life before reaching the microorganisms in indirect treatments, giving rise to new chemical species with strong bactericidal effects. However, there are also some authors (Ziuzina et al., 2015a) who did not detect differences in effectiveness between direct and indirect treatments when treating L. monocytogenes, E. coli and S. aureus biofilms.

Finally, it should be noted that, in the case of indirect treatments, another parameter that seems to determine NTAP lethality is the distance between the point of plasma generation and the sample. Thus, the results obtained by several authors show that, in general, the antimicrobial effectiveness decreases as that distance increases (Gabriel et al., 2016b; Nishime et al., 2017).

\section{Microbial-Related Factors}

One of the key advantages of NTAP in comparison to other nonthermal food preservation technologies is its ability to inactivate not only bacteria, molds and yeasts, but also mold ascospores and bacterial spores (Muranyi et al., 2007; Rowan et al., 2007; Shi et al., 2011; Klämpfl et al., 2012; Dasan et al., 2016).

In general, molds and yeasts are more tolerant against the action of plasma than bacteria, and vegetative cells are more sensitive than bacterial spores (Lee et al., 2006; Muranyi et al., 2007; Rowan et al., 2007; Hong et al., 2009; Shi et al., 2011; Klämpfl et al., 2012; Tseng et al., 2012; Takamatsu et al., 2015). However, results obtained by numerous authors studying the effectiveness of NTAP under the same experimental conditions for a wide range of microbial groups have demonstrated that 
differences in NTAP resistance among these microbial groups are not as marked as those observed for thermal and other non-thermal processing technologies.

Some studies, in particular, provide interesting insights into the inter-kingdom and inter-species variability in NTAP resistance. Klämpfl et al. (2012) evaluated the effectiveness of an air plasma for the inactivation of vegetative cells of 15 bacterial species, including E. coli. P. aeruginosa, S. aureus, E. faecalis, B. cereus, B. pumilus, and $C$. difficile, one yeast species (Candida albicans), and spores of four bacterial species ( $B$. subtilis, B. pumilus, B. atrophaeus and G. stearothermophilus). They observed that after $30 \mathrm{~s}$ of NTAP treatment, between 4 and $6 \log$ reductions were achieved for vegetative cells, while after a 1 min exposure under the same working conditions, from 1 (G. stearothermophilus) to 4 (B. subtilis) log reductions were attained for bacterial spores. Lee et al. (2006), using a plasma obtained from a mixture of helium and oxygen, also reported a higher sensitivity to NTAP for vegetative cells than for yeasts and bacterial spores, with D values of $0.3 \mathrm{~min}$ for E. coli and S. aureus, $2 \mathrm{~min}$ for S. cerevisae, and $14 \mathrm{~min}$ for B subtilis spores. Similarly, Takamatsu et al. (2015) found that treatments of around $1 \mathrm{~min}$ with a nitrogen-based plasma were required in order to achieve $6 \mathrm{log}$ cycles of inactivation for E. coli, P. aeruginosa, E. faecalis and $S$. aureus, while 5 and $15 \mathrm{~min}$ were required to achieve the same inactivation levels for Aspergillus niger and B. cereus spores, respectively. Moreover, Tseng et al. (2012) described D values of $0.50 \mathrm{~min}$ for vegetative cells of $E$. coli and B. subtilis, while D values obtained for bacterial spores of species belonging to the genus Bacillus, Geobacillus and Clostridium (B. subtilis, G. stearothermophilus, C. sporogenes, C. perfringens, C. difficile, and $C$. botulinum Type A and type B) ranged between 2.66 ( $C$. perfringens) and 8.04 (C. botulinum type A) min. Interestingly, spores of $G$. stearothermophilus, generally used as biological indicators of heat sterilization treatments given their extreme thermoresistance, showed a similar NTAP resistance to that of spores of B. subtilis, a mesophilic microorganism, suggesting that mechanisms of inactivation by heat and plasma differ, at least to a certain extent. Similar observations were also made by van Bokhorst-van de Veen et al. (2015), who hardly found differences in NTAP resistance among spores of B. cereus, $G$. stearothermophilus and B. atrophaeus, obtaining between 3.7 and $4.9 \mathrm{log}$ reductions after a $20 \mathrm{~min}$ treatment with a nitrogen-based plasma, while identified large inter-species variations in spore resistance to heat, UV light and chemical oxidants (hydrogen peroxide and sodium hypochlorite).

The higher NTAP resistance exhibited by bacterial spores may be due to the low water content and the high concentration of dipicolinic acid in the spore core, the low permeability of the spore inner membrane, the very robust spore coat, which represents a physical barrier to external agents, the special conformation of the spore DNA, which is saturated by a group of soluble acid proteins (SASP), the presence of detoxifying enzymes in the spore cortex, or the absence of metabolic activity within the spore, which limits the activity of plasma-generated components (Henriques and Moran, 2007). In a recent study by Reineke et al. (2015) analyzing two B. subtilis mutant strains, unable to synthesize dipicolinic acid during sporulation and two of the major SASPs, respectively, it was reported that only this latter strain was more sensitive to NTAP than the wild type strain, what suggested that DNA stabilization through SASPs may be responsible, at least in part, for the increased resistance of bacterial spores against NTAP.

The higher NTAP resistance exhibited by yeasts and molds in comparison to vegetative bacterial cells could be due to differences between prokaryotic and eukaryotic cells in cellular structure and molecular composition. On the one hand, the fungal genome is protected by the nuclear membrane, which constitutes an additional diffusion barrier that would contribute to increase the cell resistance to DNA damaging agents. On the other hand, the fungal cell wall is very thick and consists of rigid layers of polysaccharides, which would provide further protection to the cell (Klämpfl et al., 2012).

In relation to bacterial vegetative cells, Gram-positive bacteria are generally considered to be more resistant to NTAP than Gram-negative bacteria due to the fact that they have a thicker layer of peptidoglycan in their cell wall, which increases the rigidity of cellular envelopes, making them more resistant to mechanical damage and hindering the diffusion of reactive species through the envelopes (Lee et al., 2006; Ziuzina et al., 2014, 2015a; Edelblute et al., 2015; Jayasena et al., 2015; Yong et al., 2015a; Puligundla et al., 2017). However, other studies have found similar resistance to NTAP for particular species of both bacterial groups (Lee et al., 2006; Klämpfl et al., 2012; Tseng et al., 2012; Takamatsu et al., 2015), and, even, some authors have described strains of L. innocua (Baier et al., 2014), L. monocytogenes (Gabriel et al., 2016a), B. cereus (Marsili et al., 2002), S. aureus and E. faecalis (Nishime et al., 2017) as being more sensitive to NTAP than strains of E. coli, S. Typhimurium, S. Enteritidis, Vibrio parahaemolyticus and Pseudomonas aeruginosa, respectively. These results seem to indicate that it is not possible to draw general conclusions on whether Gram-positive and Gram-negative bacteria have differential sensitiveness against NTAP.

Intraspecific variability in NTAP resistance may also exist. Indeed, Galvin et al. (2013) and Burts et al. (2009) have reported differences of around $1 \log$ cycle of inactivation among $S$. aureus strains exposed either to helium-based or air-based plasmas. Similar results have been described by Niemira (2012) for a group of E. coli O157:H7 strains exposed to air plasmas.

It is well-known that the cellular physiological state markedly determines microbial resistance to different inactivation treatments. In fact, bacterial cells harvested during exponential growth phase are known to be more sensitive against heat, pulsed electric fields and high hydrostatic pressures than cells obtained in the stationary phase of growth (Alvarez et al., 2000; Martínez et al., 2003; Mañas and Mackey, 2004). However, based on the results available in the literature, the microbial physiological state exerts little or no influence at all on microbial resistance against NTAP. Thus, no significant differences in D-values were found among E. coli (Yu et al., 2006; Deng et al., 2007) and S. Typhimurium (Fernández et al., 2013) cultures obtained in logarithmic, early and late stationary phases of growth.

It is worth noting that NTAP treatments have been shown to be capable of inactivating different bacteria (e.g., S. aureus, E. 
faecium, L. monocytogenes, E. coli O157:H7, A. hydrophila or P. aeruginosa) in the form of biofilms (Jahid et al., 2014; Flynn et al., 2015; Ziuzina et al., 2015a,b). It is well-known that cells within biofilms exhibit increased resistance to various disinfectant agents commonly used in the food industry (Pan et al., 2006). Similarly, cells in planktonic state show a higher sensitiveness toward NTAP than cells within biofilms. For instance, Jahid et al. (2014) reported for A. hydrophila that a treatment with an oxygen plasma for $15 \mathrm{~s}$ caused a $7 \log$ reduction in planktonic cells, whereas only $3 \log$ reductions were obtained for cells forming a biofilm, even when the treatment time was prolonged for up to $5 \mathrm{~min}$. The increased NTAP resistance of cells within biofilms has been attributed to the protective effect exerted by the biofilm's extracellular matrix, constituted mainly by polymeric substances, including polysaccharides, phospholipids, proteins, nucleic acids, and teicoic acids (Shi and Zhu, 2009), which represents a physical barrier hindering the penetration of the chemical reactive species occurring in plasma, which would then require longer treatment times to exert their antimicrobial action (Vleugels et al., 2005).

Microbial resistance to various inactivation treatments is largely determined by growth conditions, especially temperature and pH (Alvarez-Ordóñez et al., 2008; Álvarez-Ordóñez et al., 2009; Alvarez-Ordóñez et al., 2010). However, little attention has been paid so far to the impact of such environmental growth conditions on the effectiveness of NTAP treatments. Very few studies have assessed the effect of growth temperature on NTAP resistance. There exists some data for $S$. Typhimurium, $S$. Enteritidis, L. monocytogenes and L. innocua, grown in the range 10-45 ${ }^{\circ} \mathrm{C}$ (Fernández et al., 2013; Calvo et al., 2016, 2017), and for A. hydrophila, grown at temperatures between 4 and $30^{\circ} \mathrm{C}$ (Jahid et al., 2014). From these studies it can be concluded that no significant differences in NTAP resistance occur at growth temperatures close to the optimum growth temperature (20 to $45^{\circ} \mathrm{C}$ ), while at temperatures below $20^{\circ} \mathrm{C}$ a minor sensitization of cells to plasma occurred. On the other hand, in the particular case of A. hydrophila cells forming biofilms, resistance to NTAP exponentially increased with increasing growth temperatures, with times required to reduce the population in $5 \mathrm{log}$ cycles being $1.84 \mathrm{~min}$ at $4^{\circ} \mathrm{C}$ and $25.33 \mathrm{~min}$ at $30^{\circ} \mathrm{C}$ (Jahid et al., 2014).

In relation to the influence of growth $\mathrm{pH}$, our research team (Calvo et al., 2016, 2017) has recently demonstrated that the growth of $S$. Typhimurium, S. Enteritidis and L. monocytogenes in media acidified with different acids (acetic, ascorbic, citric, lactic, malic, and hydrochloric) at low $\mathrm{pH}$ conditions ( $\mathrm{pH} 6.5$, 5.4 or 4.5 ) did not significantly influence the antimicrobial effectiveness of NTAP treatments. The short-term exposure of these microorganisms to acid, cold or heat stress shocks prior to NTAP treatments did no modify their resistance either. Since cross-resistance adaptive responses did not take place, these findings allowed us to conclude that NTAP may be a firstchoice technology to be included into food processing schemes following a hurdles technology approach in combination with acidification, mild heating or refrigeration.

Several authors have shown that the effectiveness of NTAP treatments decreases when dealing with high microbial loads. This fact has been shown in various substrates and for different microorganisms, including E. coli (Yu et al., 2006; Burts et al.,
2009; Miao and Yun, 2011; Bermúdez-Aguirre et al., 2013), S. aureus (Burts et al., 2009), S. Typhimurium (Fernández et al., 2012), and S. cerevisae (Lee et al., 2006). However, in the case of bacterial spores the results are not so clear. Indeed, while some authors did not find differences in NTAP effectiveness depending on the initial spore concentration for different species of the genus Bacillus (Purevdorj et al., 2001; Lee et al., 2006), in a recent study, Butscher et al. (2016) observed that when the initial load of G. stearothermophilus spores in wheat grains was reduced from $10^{7}$ to $10^{6} \mathrm{cfu} / \mathrm{g}$ the degree of inactivation achieved through a 10 min NTAP treatment increased from 1.02 to 1.82 log units.

Several authors have attempted to explain the loss of antimicrobial efficacy of NTAP on substrates with high microbial loads. Fernández et al. (2012) suggested that with high microbial loads the abundance of reactive species per cell would not be sufficient to cause their death. Even, these reactive species would react with already inactivated microorganisms or with their cellular components (e.g., proteins), which could act as sequestering agents (Kamgang-Youbi et al., 2008), thus protecting the remaining living cells. In this regard, Fernández et al. (2012) found that the addition of heatinactivated cells significantly reduced NTAP effectiveness against $S$. Typhimurium. In addition, when high microbial loads are present, microorganisms are arranged in a stacked structure, in the form of multiple layers, with the upper microbial layers, even if already inactivated, constituting a physical barrier to the penetration of plasma, therefore protecting those microorganisms located in the inner layers. This distribution of microorganisms in layers has been observed through electron microscopy for B. subtilis spores (Deng et al., 2006), as well as through fluorescence microscopy for $S$. Typhimurium (Fernández et al., 2012). However, it should be taken into account that in all the studies mentioned above, contamination levels and microbial loads were much higher than those expected in naturally contaminated food.

\section{Characteristics of the Treatment Medium or Food}

The most important factors related to the treatment medium properties determining microbial resistance to NTAP are the medium composition, in the case of liquids and liquid foods, and the topography and certain physical properties, in the case of solid foods.

For liquids, only those plasma-generated reactive species with a relatively long life, such as ozone, atomic oxygen, nitric oxide or hydrogen peroxide, would have the capacity to diffuse through the medium and interact with microbial cells (Ziuzina et al., 2013). However, NTAP has been shown to be very effective in liquid media (Montenegro et al., 2002; Shi et al., 2011; Ziuzina et al., 2013; Surowsky et al., 2014), which has been attributed to the generation of new secondary reactive species through the interaction of the chemical species of plasma with each other or with water or other molecules present in the liquid or gaseous phase of the medium. For example, the coexistence of ozone and hydrogen peroxide in water results in highly 
reactive species such as hydroperoxides and hydroxyl radicals. In addition, atomic oxygen, upon reaction with water, can generate hydrogen peroxide and singlet oxygen (Surowsky et al., 2014; Takamatsu et al., 2015), and the interaction of nitric oxide and superoxide produces peroxynitrite, a highly reactive compound that can readily diffuse through cell membranes (Ercan et al., 2016).

Several authors have reported that NTAP treatment of water and other aqueous solutions causes an increase in both their electrical conductivity and oxidation-reduction potential (Tian et al., 2015; Xu et al., 2016). In addition, several studies have detected through various analytical techniques the presence of reactive oxygen species and reactive nitrogen species in plasma treated water (Ryu et al., 2013; Surowsky et al., 2014; Ercan et al., 2016). However, apart from the presence of these highly reactive species, the rapid acidification that NTAP treatment causes in non-buffered solutions, due to the dissociation of water and the formation of nitric acid and nitrous acid if nitrogen is available, is also believed to be responsible for the inactivation capacity of NTAP in liquid media. Several authors (Rowan et al., 2007; Chen et al., 2009; Naïtali et al., 2010; Ryu et al., 2013; Ma et al., 2015) have shown that the $\mathrm{pH}$ of plasma treated water decreases gradually with treatment time up to values close to $\mathrm{pH}$ 3.0. This same behavior has been observed in non-buffered saline solutions (Oehmigen et al., 2010; Ryu et al., 2013; Ziuzina et al., 2013), which would justify the greater antimicrobial effectiveness of NTAP in these media as compared to that observed in media containing substances with buffering capacity (Chen et al., 2009; Naïtali et al., 2010; Ryu et al., 2013; Ziuzina et al., 2013). However, several authors have observed that the level of microbial inactivation attained in NTAP treated media (reaching $\sim \mathrm{pH} 3.0$ ) is much higher than that observed for media acidified at pH 3.0 with different acidulants (Chen et al., 2009; Liu et al., 2010; Naïtali et al., 2010; Ercan et al., 2016). In order to explain this behavior, several authors have speculated about the possibility that low $\mathrm{pH}$ values could contribute to the stabilization of some of the reactive species generated in plasmas (Yost and Joshi, 2015) or to the formation of new compounds with antimicrobial potential (Naïtali et al., 2010). A possible synergistic effect of low $\mathrm{pH}$ and NTAP-derived reactive species on microbial inactivation has been also proposed (Oehmigen et al., 2010; Sun et al., 2012).

The influence of treatment medium composition on plasma effectiveness in liquid media has been scarcely studied, but some reports have shown that the presence of some salts, such as carbonates, phosphates and sodium chloride (Chen et al., 2009; Ryu et al., 2013), reduce the efficacy of NTAP treatments, through reacting with the chemically active species or due to their buffering capacity. The presence of organic matter can also influence the effectiveness of NTAP. Indeed, Rowan et al. (2007) observed a greater inactivation of various enteropathogenic microorganisms in poultry washing water than in distilled water, which was attributed to the formation of nitric acid and carbonic acid from fat and proteins present in the medium. On the other hand, the inactivation of molds and yeasts in complex media has been shown to be much less effective than in a saline solution or water (Ryu et al., 2013).
Regarding microbial inactivation on solid media, NTAP is a very efficient technology for surface decontamination of abiotic surfaces, such as stainless steels, various packaging materials, paper, glass and plastics of diverse nature (Muranyi et al., 2007; Leipold et al., 2010; Miao and Yun, 2011; Klämpfl et al., 2012; Patil et al., 2014; Butscher et al., 2016; Gabriel et al., 2016b). In addition, it is also highly effective for surface decontamination of a wide variety of foods, such as fruits, vegetables, spices, nuts, cereal grains, seeds, seaweed, meat and meat products, eggs, egg products, cheese slices, and dried squid shreds (Table 2). However, microbial survival on different solids is conditioned by surface characteristics, which will determine its possible heating during NTAP treatment, the degree of microbial adhesion, as well as the level of formation and/or adsorption of active species. In particular, surface roughness, porosity and topography are of special relevance (Song et al., 2009; Noriega et al., 2011). A large number of studies have demonstrated a great variability in NTAP effectiveness against both vegetative cells and bacterial spores when identical treatments were applied onto different surfaces (Yun et al., 2010; Noriega et al., 2011; Yong et al., 2015a; Butscher et al., 2016). For example, Miao and Yun (2011) studied the inactivation of E. coli on PET (polyethylene terephthalate), PVC (polytetrafluoroethylene) and PTFE (polytetrafluoroethyleneteflon), and obtained the greatest lethal effect on PET, while the lowest inactivation was found on PTFE. These authors attributed the observed differences to differences in surface wettability of the materials, which was higher for PET, followed by PVC and, finally, PTFE. Fernández et al. (2013) obtained 2.7 log reductions in $S$. Typhimurium viability on polycarbonate filters after a $2 \mathrm{~min}$ NTAP treatment, while it took 15 min to reach $2.7 ; 1.8$ and 0.9 $\log$ cycles of inactivation on lettuce, strawberries and cut potato, respectively. Similarly, Lee et al. (2011) and Butscher et al. (2016), comparing the effectiveness of NTAP for the inactivation of $L$. monocytogenes and G. stearothermophilus on abiotic surfaces and foods, observed that the highest antimicrobial activities were obtained on abiotic surfaces, such as agar plates or polypropylene grains. In addition, it has also been demonstrated that the effectiveness of NTAP as a food decontamination technique varies among different foods. Thus, inactivation of $E$. coli was more effective on tomato than on lettuce (Bermúdez-Aguirre et al., 2013) or strawberries (Ziuzina et al., 2014), also being faster on carrots than on apples (Baier et al., 2015). For $L$. monocytogenes a greater lethal effect was also observed on cheese slices than on ham (Song et al., 2009), on sliced ham than on chicken breast filets (Lee et al., 2011), or on tomato than on strawberries (Ziuzina et al., 2014). These results show that food topography should be taken into account when designing effective NTAP treatments. Additionally, differences can be also attributed to the fact that bacteria could have been in the form of planktonic cultures on the surface, biofilms or internalized in the food tissues, and it is well-known that this can show a very important influence on the inactivation effectiveness of NTAP (Ziuzina et al., 2015b; Berardinelli et al., 2016).

Overall, there is a unanimous agreement in that on smooth and polished surfaces the anti-microbial efficiency of NTAP is very high (Noriega et al., 2011; Bermúdez-Aguirre et al., 2013; Fernández et al., 2013; Kim et al., 2014; Butscher et al., 
TABLE 2 | Summary of major research articles assessing the level of microbial inactivation achieved and the quality changes occurring in foods subjected to non-thermal atmospheric plasma treatments.

\begin{tabular}{|c|c|c|c|c|}
\hline Product & Treatment regime & Maximal log reduction & Impact on quality attributes & References \\
\hline \multicolumn{5}{|c|}{ MEAT AND MEAT PRODUCTS } \\
\hline Pork loin & $\begin{array}{l}\text { He or mixtures } \mathrm{He}+\mathrm{O}_{2} \\
10 \text { slpm; } 3 \mathrm{kV} ; 30 \mathrm{kHz} \\
3 \mathrm{~mm} \text { distance }\end{array}$ & $\begin{array}{l}\text { Listeria monocytogenes } \sim 0.59 \mathrm{log} \\
\text { Escherichia coli } \sim 0.55 \mathrm{log} \text {, in } 10 \mathrm{~min}\end{array}$ & $\begin{array}{l}\text { Loss of lightness. Significant reductions in } \\
\text { sensory quality parameters (appearance, } \\
\text { color, odor, acceptability). }\end{array}$ & Kim et al., 2013 \\
\hline Pork & $\begin{array}{l}\text { Mixtures of } \mathrm{N}_{2} \text { and } \mathrm{O}_{2} \\
15 \mathrm{kHz} ; 2 \mathrm{~W}\end{array}$ & $\begin{array}{l}\text { Listeria monocytogenes } \sim 2.0 \mathrm{log} \\
\text { Escherichia coli O157:H7 2.5 log } \\
\text { Salmonella Typhimurium } \sim 2.7 \mathrm{log}, \\
\text { in } 10 \text { min }\end{array}$ & $\begin{array}{l}\text { Minor changes in color and taste. No } \\
\text { effects in texture. }\end{array}$ & $\begin{array}{l}\text { Jayasena et al., } \\
2015\end{array}$ \\
\hline $\begin{array}{l}\text { Frozen and unfrozen } \\
\text { pork }\end{array}$ & $\begin{array}{l}\text { Air; } 2.5 \mathrm{~m} / \mathrm{s} ; 20 \mathrm{kV} \\
58 \mathrm{kHz} ; 25 \mathrm{~mm} \\
\text { distance }\end{array}$ & $\begin{array}{l}\text { Listeria monocytogenes 1.0 log } \\
\text { Escherichia coli O157:H7 } \sim 1.5 \mathrm{log}, \\
\text { in } 2 \mathrm{~min}\end{array}$ & $\begin{array}{l}\text { Only significant impact on the sensory } \\
\text { characteristics (color and appearance) of } \\
\text { unfrozen pork }\end{array}$ & Choi et al., 2016 \\
\hline Beef & $\mathrm{N}_{2}+\mathrm{O}_{2} ; 15 \mathrm{kHz} ; 2 \mathrm{~W}$ & $\begin{array}{l}\text { Listeria monocytogenes } \sim 1.9 \mathrm{log} \\
\text { Escherichia coli O157:H7 } 2.6 \mathrm{log} \\
\text { Salmonella Typhimurium } \sim 2.6 \mathrm{log}, \\
\text { in } 10 \text { min }\end{array}$ & $\begin{array}{l}\text { Minor changes in color and taste. No } \\
\text { effects in texture. }\end{array}$ & $\begin{array}{l}\text { Jayasena et al., } \\
2015\end{array}$ \\
\hline $\begin{array}{l}\text { Chicken meat and } \\
\text { skin }\end{array}$ & $\begin{array}{l}\mathrm{He}(5 \mathrm{~L} / \mathrm{min})+\mathrm{O}_{2}(100 \\
\mathrm{mL} / \mathrm{min}) ; 16 \mathrm{kV} \\
30 \mathrm{kHz} ; 1 \mathrm{~cm} \text { distance }\end{array}$ & $\begin{array}{l}\text { Listeria innocua } \sim 1.0 \mathrm{log} \text { on skin, in } 8 \mathrm{~min} \\
>3.0 \text { log on meat, in } 4 \mathrm{~min}\end{array}$ & Not assessed & $\begin{array}{l}\text { Noriega et al., } \\
2011\end{array}$ \\
\hline $\begin{array}{l}\text { Chicken breast and } \\
\text { thigh }\end{array}$ & Air & $\begin{array}{l}\text { Salmonella enterica } \sim 2.5 \mathrm{log} \\
\text { Campylobacter jejuni } \sim 2.4 \mathrm{log} \text {, in } 3 \mathrm{~min}\end{array}$ & Not assessed & Dirks et al., 2012 \\
\hline \multirow[t]{2}{*}{ Beef jerky } & $\begin{array}{l}\text { Ar; 20,000 sccm; } \\
200 \mathrm{~W} ; 1 \mathrm{~cm} \text { distance }\end{array}$ & Staphycococcus aureus $\sim 1.8 \mathrm{log}$, in $8 \mathrm{~min}$ & No changes in texture and color & Kim et al., 2014 \\
\hline & Air; $15 \mathrm{kHz}$ & $\begin{array}{l}\text { Listeria monocytogenes, } \sim 2.4 \mathrm{log} \\
\text { Escherichia coli O157:H7, } 2.7 \mathrm{log} \\
\text { Salmonella Typhimurium, } \sim 3.0 \mathrm{log} \\
\text { Aspergillus flavus, } \sim 3.2 \mathrm{log}, \text { in } 10 \mathrm{~min}\end{array}$ & $\begin{array}{l}\text { No significant changes in metmyoglobin } \\
\text { content, shear force, and myofibrillar } \\
\text { fragmentation index; changes in peroxides } \\
\text { content and color parameters; negative } \\
\text { effects on flavor, off-odor, and overall } \\
\text { acceptability }\end{array}$ & Yong et al., 2017 \\
\hline $\begin{array}{l}\text { Cooked chicken } \\
\text { breast }\end{array}$ & $\begin{array}{l}\mathrm{N}_{2}(7 \mathrm{~L} / \mathrm{min})+\mathrm{O}_{2}(0.07 \\
\mathrm{L} / \mathrm{min}) ; 2 \mathrm{kV} ; 50 \mathrm{kHz} \\
4 \mathrm{~cm} \text { distance }\end{array}$ & Listeria monocytogenes $\sim 4.7 \mathrm{log}$, in $2 \mathrm{~min}$ & Not assessed & Lee et al., 2011 \\
\hline Cooked ham & $\begin{array}{l}\mathrm{N}_{2}(7 \mathrm{~L} / \mathrm{min})+\mathrm{O}_{2}(0.07 \\
\mathrm{L} / \mathrm{min}) ; 2 \mathrm{kV} ; 50 \mathrm{kHz} ; 4 \\
\text { com distance }\end{array}$ & Listeria monocytogenes $\sim 6.5 \mathrm{log}$, in $2 \mathrm{~min}$ & Not assessed & Lee et al., 2011 \\
\hline Ham & $\begin{array}{l}\mathrm{He} ; 13.56 \mathrm{MHz} ; 150 \mathrm{~W} \\
\text { 0,6 mm distance }\end{array}$ & Listeria monocytogenes $\sim 1.7 \mathrm{log}$, in $2 \mathrm{~min}$ & Not assessed & Song et al., 2009 \\
\hline Bacon & $\begin{array}{l}\mathrm{He}(10 \mathrm{~L} / \mathrm{min})+\mathrm{O}_{2}(10 \\
\mathrm{sccm}) ; 13,56 \mathrm{MHz} \\
125 \mathrm{~W} ; 3 \mathrm{~mm} \text { distance }\end{array}$ & $\begin{array}{l}\text { Listeria monocytogenes } \sim 2.6 \mathrm{log} \\
\text { Escherichia coli } \sim 3.0 \mathrm{log} \\
\text { Salmonella Typhimurium } \sim 1.0 \mathrm{log}, \\
\text { Total aerobic bacteria } \sim 4.6 \mathrm{log}, \text { in } 1.5 \mathrm{~min}\end{array}$ & $\begin{array}{l}\text { No physical damage on surface tissues. } \\
\text { Higher lightness. Lipid oxidation was not } \\
\text { observed }\end{array}$ & Kim et al., 2011 \\
\hline Bresaola & $\begin{array}{l}\operatorname{Ar}(70 \%)+\mathrm{O}_{2}(30 \%) \\
27.8 \mathrm{kV} ; 15.5 \mathrm{~W}\end{array}$ & Listeria innocua $>1.5 \mathrm{log}$, in $10 \mathrm{~s}$ & Loss of redness, Induced lipid oxidation. & Rød et al., 2012 \\
\hline \multicolumn{5}{|l|}{ DAIRY PRODUCTS } \\
\hline \multirow[t]{2}{*}{ Cheese } & $\begin{array}{l}\mathrm{He} ; 13.56 \mathrm{MHz} ; 150 \mathrm{~W} ; \\
0,6 \mathrm{~mm} \text { distance }\end{array}$ & Listeria monocytogenes $\sim 8.5 \mathrm{log}$, in $2 \mathrm{~min}$ & Not assessed & Song et al., 2009 \\
\hline & Air; $15 \mathrm{kHz} ; 250 \mathrm{~W}$ & $\begin{array}{l}\text { Escherichia coli } \sim 2.7 \mathrm{log} \text {, in } 1 \mathrm{~min} \\
\text { Salmonella Typhimurium } \sim 3.1 \mathrm{log} \text {, in } 45 \mathrm{~s}\end{array}$ & Not assessed & Yong et al., $2015 a$ \\
\hline Cheddar cheese & Air; $15 \mathrm{kHz} ; 2 \mathrm{~W}$ & $\begin{array}{l}\text { Listeria monocytogenes } \sim 5.8 \mathrm{log} \\
\text { Escherichia coli O157:H7 } 3.6 \mathrm{log} \\
\text { Salmonella Typhimurium } \sim 2.1 \mathrm{log}, \\
\text { in } 10 \text { min }\end{array}$ & $\begin{array}{l}\text { No changes in color and sensory } \\
\text { appearance. Significant reductions in } \\
\text { flavor and overall acceptance. Increased } \\
\text { off-odor }\end{array}$ & Yong et al., 2015b \\
\hline \multicolumn{5}{|l|}{ EGGS } \\
\hline Cooked egg white & $\begin{array}{l}\mathrm{N}_{2}(7 \mathrm{~L} / \mathrm{min})+\mathrm{O}_{2}(0.07 \\
\mathrm{L} / \mathrm{min}) ; 2 \mathrm{kV} ; 50 \mathrm{kHz} \\
4 \mathrm{~cm} \text { distance }\end{array}$ & $\begin{array}{l}\text { Listeria monocytogenes } \sim 6.7 \mathrm{log} \\
\text { Total aerobic bacteria } \sim 2.9 \mathrm{log}, \text { in } 2 \mathrm{~min}\end{array}$ & $\begin{array}{l}\text { Loss of lightness. No impact on sensory } \\
\text { attributes (color, flavor, texture, taste, } \\
\text { acceptability). }\end{array}$ & Lee et al., 2012b \\
\hline Cooked egg yolk & $\begin{array}{l}\mathrm{N}_{2}(7 \mathrm{~L} / \mathrm{min})+\mathrm{O}_{2}(0.07 \\
\mathrm{L} / \mathrm{min}) ; 2 \mathrm{kV} ; 50 \mathrm{kHz} \\
4 \mathrm{~cm} \text { distance }\end{array}$ & $\begin{array}{l}\text { Listeria monocytogenes } \sim 7.1 \mathrm{log} \\
\text { Total aerobic bacteria } \sim 2.3 \mathrm{log}, \text { in } 2 \mathrm{~min}\end{array}$ & $\begin{array}{l}\text { Loss of lightness. Significant reductions in } \\
\text { flavor, taste and overall acceptability }\end{array}$ & Lee et al., 2012b \\
\hline
\end{tabular}


TABLE 2 | Continued

\begin{tabular}{|c|c|c|c|c|}
\hline Product & Treatment regime & Maximal log reduction & Impact on quality attributes & References \\
\hline \multicolumn{5}{|c|}{ FISH AND SEAFOOD } \\
\hline Dried squid shreds & $\begin{array}{l}\text { Air; } 2 \mathrm{~L} / \mathrm{s} ; 20 \mathrm{kV} \text {; } \\
58 \mathrm{kHz} ; 25 \mathrm{~mm} \\
\text { distance }\end{array}$ & $\begin{array}{l}\text { Staphylococcus aureus } \sim 0.9 \mathrm{log} \\
\text { Marine bacteria } \sim 1.6 \mathrm{log} \\
\text { Aerobic bacteria } \sim 2.0 \mathrm{log} \\
\text { Yeast and molds } \sim 0.9 \mathrm{log}, \text { in } 3 \mathrm{~min}\end{array}$ & $\begin{array}{l}\text { No significant changes in color } \\
\text { characteristics and volatile basic nitrogen } \\
\text { content; moisture and thiobarbituric acid } \\
\text { reactive substances levels were altered; no } \\
\text { significant impact on sensory } \\
\text { characteristics (color, flavor, taste, texture, } \\
\text { acceptability, overall acceptance) }\end{array}$ & Choi et al., 2017 \\
\hline \multicolumn{5}{|c|}{ FRUIT, CEREALS AND VEGETABLES } \\
\hline Blueberries & $\begin{array}{l}\text { Air; } 4 \text { cfm; } 47 \mathrm{KHz} \text {; } \\
549 \mathrm{~W} ; 7.5 \mathrm{~cm} \text { distance }\end{array}$ & $\begin{array}{l}\text { Total aerobic count } \sim 0.8 \mathrm{log} \\
\text { Yeast and molds } \sim 1.2 \mathrm{log}, \text { in } 2 \mathrm{~min}\end{array}$ & $\begin{array}{l}\text { Significant reductions in firmness and } \\
\text { anthocyanins; surface color was } \\
\text { significantly impacted }\end{array}$ & $\begin{array}{l}\text { Lacombe et al., } \\
2015\end{array}$ \\
\hline Strawberries & $\begin{array}{l}\text { Air; } 70 \mathrm{kV} ; 50 \mathrm{~Hz} \\
140-160 \mathrm{~mm} \text { distance }\end{array}$ & $\begin{array}{l}\text { Listeria monocytogenes } \sim 4.2 \mathrm{log} \\
\text { Escherichia coli O157:H7 } \sim 3.5 \mathrm{log} \\
\text { Salmonella Typhimurium } \sim 3.8 \mathrm{log} \text {, in } 5 \mathrm{~min}\end{array}$ & Not assessed & Ziuzina et al., 2014 \\
\hline Pears & Air; 5 slm; $500 \mathrm{~V}$ & Salmonella spp. $\sim 0.2 \mathrm{log}$, in $0.5 \mathrm{~s}$ & $\begin{array}{l}\text { Changes in physiochemical properties } \\
\text { were within an acceptable range }\end{array}$ & Wang et al., 2012 \\
\hline Apples & $\begin{array}{l}\operatorname{Ar}(5 \mathrm{~L} / \mathrm{min})+\mathrm{O}_{2} \\
(0.1 \%) ; 10 \mathrm{kV} ; 8 \mathrm{~W} \\
17 \mathrm{~mm} \text { distance }\end{array}$ & Escherichia coli $\sim 4.7 \mathrm{log}$, in $1 \mathrm{~min}$ & Not assessed & Baier et al., 2014 \\
\hline Cherry tomatoes & $\begin{array}{l}\text { Air; } 70 \mathrm{kV} ; 50 \mathrm{~Hz} \\
140-160 \mathrm{~mm} \text { distance }\end{array}$ & $\begin{array}{l}\text { Listeria monocytogenes } \sim 6.7 \mathrm{log} \text {, in } 2 \mathrm{~min} \\
\text { Escherichia coli } \sim 3.1 \mathrm{log} \text {, in } 1 \mathrm{~min} \\
\text { Salmonella Typhimurium } \sim 6.3 \mathrm{log} \text {, in } 10 \mathrm{~s} \\
\text { Aerobic mesophilic bacteria } \sim 4.0 \mathrm{log} \text {, in } \\
2 \mathrm{~min} \\
\text { Yeast and molds } \sim 5.0 \mathrm{log} \text {, in } 2 \mathrm{~min}\end{array}$ & Not assessed & Ziuzina et al., 2014 \\
\hline Tomato & $\begin{array}{l}\operatorname{Ar}(5 \mathrm{~L} / \mathrm{min})+\mathrm{O}_{2} \\
(0.1 \%) ; 10 \mathrm{kV} ; 8 \mathrm{~W} \\
17 \mathrm{~mm} \text { distance }\end{array}$ & Escherichia coli $\sim 3.3 \mathrm{log}$, in $1 \mathrm{~min}$ & Not assessed & Baier et al., 2014 \\
\hline Corn salad & $\begin{array}{l}\operatorname{Ar}(5 \mathrm{~L} / \mathrm{min})+\mathrm{O}_{2} \\
(0.1 \%) ; 10 \mathrm{kV} ; 8 \mathrm{~W} ; \\
17 \mathrm{~mm} \text { distance }\end{array}$ & Escherichia coli $\sim 4.1 \mathrm{log}$, in $1 \mathrm{~min}$ & No changes in color were observed & Baier et al., 2014 \\
\hline \multirow[t]{2}{*}{ Cucumber } & Air; 5 slm; $500 \mathrm{~V}$ & Salmonella spp. $\sim 0.4 \mathrm{log}$, in $0.5 \mathrm{~s}$ & $\begin{array}{l}\text { Changes in physiochemical properties } \\
\text { were within an acceptable range }\end{array}$ & Wang et al., 2012 \\
\hline & $\begin{array}{l}\operatorname{Ar}(5 \mathrm{~L} / \mathrm{min})+\mathrm{O}_{2} \\
(0.1 \%) ; 10 \mathrm{kV} ; 8 \mathrm{~W} \\
17 \mathrm{~mm} \text { distance }\end{array}$ & Escherichia coli $\sim 4.7 \mathrm{log}$, in $1 \mathrm{~min}$ & Not assessed & Baier et al., 2014 \\
\hline \multirow[t]{2}{*}{ Carrots } & Air; 5 slm; $500 \mathrm{~V}$ & Salmonella spp. $\sim 1.0 \mathrm{log}$, in $0.5 \mathrm{~s}$ & $\begin{array}{l}\text { Changes in physiochemical properties } \\
\text { were within an acceptable range }\end{array}$ & Wang et al., 2012 \\
\hline & $\begin{array}{l}\text { Air (20 L/min); } 2.45 \\
\text { Ghz; } 1.2 \mathrm{~kW}\end{array}$ & $\begin{array}{l}\text { Escherichia coli } \sim 4.5 \mathrm{log} \\
\text { Mesophilic aerobic counts } \sim 3.5 \mathrm{log} \text {, } \\
\text { in } 2 \mathrm{~min}\end{array}$ & $\begin{array}{l}\text { Significant effects on color. No impact on } \\
\text { elastic properties }\end{array}$ & Baier et al., 2015 \\
\hline Lettuce & Air; 4.5 com distance & Aeromonas hydrophila 5 log, in $15 \mathrm{~s}$ & Not assessed & Jahid et al., 2014 \\
\hline Rapeseed seeds & $\begin{array}{l}\text { Air (2 L/min); } 20 \mathrm{kV} \text {; } \\
58 \mathrm{kHz} ; 25 \mathrm{~mm} \\
\text { distance }\end{array}$ & $\begin{array}{l}\text { Escherichia coli } \sim 2.0 \mathrm{log} \\
\text { Bacillus cereus } \sim 1.2 \mathrm{log} \\
\text { Salmonella spp. } \sim 1.8 \mathrm{log} \\
\text { Total aerobic bacteria } \sim 2.2 \mathrm{log} \\
\text { Yeast and molds } \sim 2.0 \mathrm{log}, \text { in } 3 \mathrm{~min}\end{array}$ & $\begin{array}{l}\text { Physicochemical (weight, length, moisture } \\
\text { content) and sensory characteristics } \\
\text { (appearance, color, flavor, taste, texture) } \\
\text { were unaffected. }\end{array}$ & $\begin{array}{l}\text { Puligundla et al., } \\
2017\end{array}$ \\
\hline Orange juice & $\begin{array}{l}\text { Air; } 20 \mathrm{kV} ; 60 \mathrm{kHz} ; 1.14 \\
\mathrm{~W} / \mathrm{cm}^{2} ; \text { batch }\end{array}$ & $\begin{array}{l}\text { Escherichia coli } \sim 5.0 \mathrm{log} \text {, in } 8 \mathrm{~s} \\
\text { Staphylococcus aureus } \sim 5.0 \mathrm{log} \text {, in } 12 \mathrm{~s} \\
\text { Candida albicans } \sim 5.0 \mathrm{log} \text {, in } 25 \mathrm{~s}\end{array}$ & $\begin{array}{l}\text { Almost no effect on vitamin } \mathrm{C} \text { content, } \mathrm{pH} \text {, } \\
\text { turbidity or }{ }^{\circ} \text { Brix }\end{array}$ & Shi et al., 2011 \\
\hline Black peppercorns & $\begin{array}{l}\text { Air }(20 \mathrm{~L} / \mathrm{min})+\operatorname{Ar}(14 \\
\mathrm{L} / \mathrm{min}) ; 4 \mathrm{~cm} \text { distance }\end{array}$ & Salmonella $~ 5.0 \mathrm{log}$, in $80 \mathrm{sec}$ & Minimal changes in color & Sun et al., 2014 \\
\hline \multirow[t]{2}{*}{ Almonds } & Air; 30 kV; 2 kHz & Escherichia coli 5 log, in $30 \mathrm{sec}$ & Not assessed & Deng et al., 2007 \\
\hline & $\begin{array}{l}\text { Air; } 47 \mathrm{kHz} ; 549 \mathrm{~W} \text {; } \\
6 \mathrm{~cm} \text { distance }\end{array}$ & $\begin{array}{l}\text { Escherichia coli } 0157: \mathrm{H} 7 \sim 1.34 \mathrm{log} \text {, in } \\
20 \mathrm{~s}\end{array}$ & $\begin{array}{l}\text { No gross changes in color, aroma and } \\
\text { surface features }\end{array}$ & Niemira, 2012 \\
\hline Wheat grains & $\begin{array}{l}\operatorname{Ar}(28 \mathrm{~L} / \mathrm{min}) ; 8 \mathrm{kV} ; \\
10 \mathrm{kHz}\end{array}$ & $\begin{array}{l}\text { Geobacillus stearothermophillus spores } \\
\sim 3.0 \mathrm{log} \text {, in } 60 \mathrm{~min}\end{array}$ & $\begin{array}{l}\text { Functional wheat grain properties (falling } \\
\text { number, gluten content) were not } \\
\text { negatively affected. }\end{array}$ & $\begin{array}{l}\text { Butscher et al., } \\
2016\end{array}$ \\
\hline
\end{tabular}

slpm, standard liters per minute; sccm, standard cubic centimeters per minute; cfm, cubit feet meter. 
2016; Cui et al., 2016a), whereas rough, porous and irregular surfaces, such as those of some foods, offer numerous places for microorganisms to fix and hide, thus avoiding the action of plasma (Fernández et al., 2012; Bermúdez-Aguirre et al., 2013; Butscher et al., 2016; Cui et al., 2016a). In fact, some studies using electron microscopy have shown that inoculated microorganisms are capable of finding shelter within various food irregularities, such as cracks, grooves or gaps (Fernández et al., 2013; Jahid et al., 2014; Ziuzina et al., 2014; Cui et al., 2016a).

\section{APPLICATIONS OF NTAP IN THE FOOD INDUSTRY}

Once the mechanisms of microbial inactivation by NTAP and the factors that determine its lethal efficacy have been described, the following section of the review article will discuss the potential of this novel technology for specific applications within food processing industries.

\section{NTAP as a Decontamination Technique}

NTAP can be used as a decontamination technique for foods, packaging materials, equipment, and even the processing environment itself.

In relation to surface decontamination of foods, several studies have shown the potential of NTAP to improve the microbiological quality of a wide range of solid foods, including strawberries, tomatoes, chicken breast filets, ham, cheese slices, carrots, melon, or lettuce, and liquid foods, such as milk, apple and orange juices, and coconut liquid endosperm (Table 2). Although microbial inactivation rates obtained widely vary among studies, surfaces and microbial species tested, promising results have been reported. For example, with 2 min treatments, 4 to 8 logarithmic reductions were obtained for L. monocytogenes in tomatoes, cooked chicken breast filets and ham, cooked egg white and egg yolk, and cheese slices (Song et al., 2009; Lee et al., 2011, 2012b; Ziuzina et al., 2014), and 4.5 log units for E. coli in carrots (Baier et al., 2015a). Even treatments as short as 10 and $15 \mathrm{~s}$ have been able to reduce the population of $A$. hydrophila in lettuce in 5 log cycles (Jahid et al., 2014) and that of $S$. Typhimurium in tomatoes in $6 \mathrm{log}$ units (Ziuzina et al., 2014). However, most studies have not evaluated the impact of NTAP treatments on the nutritional and sensory properties of such foods, despite the fact that plasma-generated reactive species could lead to organoleptic changes in the end product. Moreover, information available in the literature is very variable, with some authors identifying minor changes in color, texture, appearance, taste or aroma of foods, while others have reported important modifications in sensory attributes after NTAP treatment (Table 2). The observed discrepancies are probably due to the variability in equipment, plasma generation conditions or type of food used in validation studies. Indeed, several authors have shown how these factors influence the maintenance of food sensory attributes. For example, the application of similar NTAP treatments significantly modified the color of carrots (Baier et al., 2015) and the taste of cooked egg yolk (Lee et al., 2012b), but did not affect these quality attributes in apples and cooked egg white, respectively. Moreover, NTAP treatments using helium as working gas caused changes in pork loin color, whereas this quality attribute was not modified in treatments using a mixture of helium and oxygen (Kim et al., 2013). Baier et al. (2014) also reported changes in leaf lettuce color after a NTAP treatment, which only occurred when the distance between food and plasma generation source was low (5 mm). Furthermore, Rød et al. (2012) described that an increase in potency, treatment time and storage time was accompanied by an increased lipid oxidation and rancidity of bresaola. Similarly, a NTAP treatment of 5-10 min has been shown to induce lipid oxidation in cheese samples (Yong et al., 2015b). However, no significant changes in the fatty acid composition of beef jerky were detected after exposure to plasma for $5 \mathrm{~min}$ (Kim et al., 2014).

Although the vast majority of studies have focused on evaluating the potential of NTAP for the decontamination of solid foods, some authors have addressed its efficacy in liquid foods, obtaining also in some occasions promising results. Thus, up to $5 \log$ reductions have been obtained for $E$. coli in orange and apple juice after a treatment of 8 and $40 \mathrm{~s}$, respectively, and treatments of 12 and $25 \mathrm{~s}$ had a similar lethality effect for $S$. aureus and Candida albicans, respectively (Shi et al., 2011; Liao et al., 2018).

NTAP can be also used for the decontamination of food packaging materials. Currently, the most widely used methods with this aim are based on the employment of dry or wet heat or chemical agents, such as peracetic acid or hydrogen peroxide, which can be applied at relatively high temperatures, ranging from 65 to $80^{\circ} \mathrm{C}$, to increase their effectiveness. However, most polymers used as packaging materials do not withstand high temperatures. In addition, some chemical agents also present other drawbacks, such as their difficult handling, maximum limits allowed and the possible generation of toxic waste substances. NTAP is an attractive alternative to chemical decontamination agents, due to its effectiveness as a decontamination technique which successfully inactivates microorganisms, including bacterial and fungal spores, on abiotic surfaces (Muranyi et al., 2007, 2008, 2010; Klämpfl et al., 2012). For example, Muranyi et al. (2007), assessing the efficacy of NTAP for the inactivation of vegetative cells ( $E$. coli, $S$. aureus, $S$. Mons, and D. radiodurans), bacterial spores (B. atrophaeus, B. pumilus, C. botulinum, C. sporogenes) and fungi spores (A. niger) on PET, achieved, with treatment times as short as 1 second, between 5.6 and $6.9 \log$ reductions for vegetative cells, between 5.1 and 6.1 $\log$ reductions for bacterial spores and $3 \log$ reductions for $A$. niger conidiospores.

NTAP can even be used for the decontamination of food once packaged, using dielectric barrier discharge equipment (Fröhling et al., 2012a; Rød et al., 2012; Ziuzina et al., 2014; Jayasena et al., 2015). The reactive species generated in this case would simultaneously decontaminate both the packaging material and the food itself. Moreover, once the treatment concludes, the plasma species recombine, the atmosphere returns to its initial composition, and recontamination of the end product after NTAP treatment is thus avoided. The use of NTAP for the decontamination of food once packaged, has been successfully 
studied in cherry tomatoes, strawberries, bresaola and pork and beef meat by several research groups (Fröhling et al., 2012a; Rød et al., 2012; Ziuzina et al., 2014; Jayasena et al., 2015).

Another potential application of NTAP in the food industry is the decontamination of food processing surfaces and equipment. In fact, a novel plasma system has been designed to decontaminate slicers, in which the cutting blade of the equipment constitutes one of the electrodes of the dielectric discharge system (Leipold et al., 2010). These authors obtained an effective inactivation of L. innocua inoculated on the cutting blade, representing a novel approach for decontaminating food processing equipment which could be applied to other surfaces, such as conveyors.

Recently, several authors have described the fact that water treated by NTAP, so-called plasma-activated water (PAW), has relevant antimicrobial activity, which persist over a long period of time (Kamgang-Youbi et al., 2009; Ercan et al., 2013; Zhang et al., 2013). This offers new possibilities for decontamination of both surfaces and food, through the treatment of water by NTAP, which will be then used for decontamination purposes. This approach may be a promising alternative to the chemical agents currently used for the sanitation of surfaces, equipment and minimally processed vegetables. In fact, the potential of plasma-activated water has recently been revealed for the decontamination of strawberries (Ma et al., 2015) and mushrooms (Xu et al., 2016). Indeed, a bactericidal effect similar to that obtained using sodium hypochlorite solutions (IssaZacharia et al., 2010), with no changes in color or firmness, was observed for strawberries treated with plasma-activated water, with $\log$ reductions for $S$. aureus ranging from 1.7 to 2.3 log depending on the exposure time (Ma et al., 2015). Log reductions achieved following a similar approach for treated mushrooms were between 1.5 and $0.7 \log$ after a week of storage, and mushrooms maintained their initial quality attributes (Xu et al., 2016).

\section{Other Applications of NTAP in Food Processing}

Apart from being used as a decontamination technique, NTAP may also represent an alternative food processing method which can be used, for example, to obtain the characteristic color of cured meat products without adding nitrites, extend the shelflife of oils used for coating cookies, reduce the cooking time of cereals, improve the extraction of essential oils or modify the functional properties of flours.

As already mentioned, the interaction of plasma with water results in the generation of reactive oxygen and nitrogen species, including nitrates and nitrites (Oehmigen et al., 2010), reaching concentrations of up to $1,050 \mathrm{ppm}$ (Hao et al., 2014). The generation of nitrites during plasma treatment may raise a flag since use of nitrites in food is restricted, with maximum allowed concentrations, due to their potential toxicological effects. However, Jung et al. (2015) manufactured frankfurters by replacing the nitrites of the curing salts by plasma-treated water and did not detect significant differences in their microbiological or organoleptic quality during 28 days of storage at refrigeration.
Interestingly, the residual nitrite content was 30\% lower in sausages processed with plasma-treated water. Similar results have been also obtained by directly treating the meat butter with NTAP at different stages of the sausage making process, and a patent for NTAP as a system to eliminate nitrites in meat products has been recently filed (Lim et al., 2015).

NTAP can be used to modify the surface properties of various materials, such as paper, polymers or electronic equipment, to confer them certain functional properties of interest. The idea of using this technology to achieve surface modifications in foods is innovative. NTAP has been used to modulate hydrophobicity or hydrophilicity of oil coatings on cookies, in order to improve palatability and appearance (Misra et al., 2014). These authors demonstrated that NTAP increased surface hydrophobicity, resulting in a greater extension of the incorporated oil and in a more accurate infiltration of oil, without affecting the color, odor and appearance of cookies. Thus, it allowed the preservation of the functionality of the sprayed oil, also decreasing the amount of oil required, which is interesting from a nutritional and economic point of view. A modification of surface properties after NTAP treatments has also been observed for basmati rice (Thirumdas et al., 2015). In this case, NTAP increased the hydrophilicity and water absorption rate of the cereal, and decreased the cooking time, from 20 to $13 \mathrm{~min}$. Electron microscopy images of the treated rice grains revealed the presence of cracks and depressions on their surface, which probably provide routes for faster absorption of water. Although this experiment was carried out under vacuum conditions, which does not allow a direct extrapolation of the results, similar results are expected at atmospheric pressure conditions. Similarly, NTAP is currently being also proposed as a promising technology for the physicochemical modification of processing surfaces, such as those of

TABLE 3 | Suggested information to be provided in research studies related to non-thermal atmospheric plasma.

\begin{tabular}{ll} 
Category & Variable and minimum description to be included \\
\hline Process equipment & $\begin{array}{l}\text { Type of equipment, type of discharge, and electrode } \\
\text { configuration } \\
\text { Equipment model and vendor name } \\
\text { Distance between the point of plasma generation and } \\
\text { the sample } \\
\text { Type of gas } \\
\text { Grocessing conditions flow rate and gas moisture content } \\
\text { Energy supplied: voltage, power, and frequency } \\
\text { Processing time } \\
\text { Composition of the generated plasma } \\
\text { Type of food or sample: detailed description } \\
\text { Water activity, pH and composition of the sample } \\
\text { Time-temperature history } \\
\text { Genus, species, and strain(s) used } \\
\text { Initial microbial load } \\
\text { Pre-history of the microbial inoculum } \\
\text { Description of the procedure followed for preparing the } \\
\text { inoculum and enumerating microorganisms }\end{array}$ \\
Microbial factors &
\end{tabular}


food-contact materials, in a way to prevent microbial adhesion and formation of biofilms, therefore limiting episodes of food cross-contamination with persistent microorganisms colonizing food processing environments. These surface modification techniques are sometimes focused at changing electronegativity, hydrophobicity or morphology/topography of surfaces (Bazaka et al., 2015).

Another possible application of NTAP is its use to improve those processes that involve mass transfer. Indeed, exposure of lemon skins to plasma has been shown to increase the yield of extracted essential oils (Kodama et al., 2014). However, these results should be taken with caution, since essential oils can be oxidized to a certain extent, depending on the gas used for NTAP generation.

Finally, NTAP has been also evaluated as a methodology capable of inducing modifications in the functional properties of proteins. Misra et al. (2015) showed that the secondary structure of gluten became more stable when wheat flour had been treated with an air plasma, and observed significant changes in the rheological properties of the doughs obtained. These changes, both in viscosity and elasticity, depended on the treatment conditions, applied voltage and exposure time. Thus, NTAP can be used as an innovative strategy in order to modulate the functionality of wheat flour during processing of bread, pasta, noodles, cookies, and others.

\section{CONCLUSIONS AND FUTURE PROSPECTS}

NTAP is a promising food decontamination technology capable of inactivating bacteria, yeasts, molds, fungal and bacterial spores both on abiotic surfaces (e.g., packaging materials, food processing environments and equipment) and on foods. In addition, NTAP has also other different innovative applications of great interest for food quality and safety improvement.

Although the exact mechanism of microbial inactivation by NTAP is not completely known yet, the cellular envelopes, DNA and proteins are recognized as potential targets, and damages produced to them are the result of the simultaneous action of the different components and reactive species occurring in plasma when the microbial detoxifying capacity is overcome, resulting in the accumulation of dysfunctional macromolecules that compromise cellular viability. The multi-target nature of NTAP could justify the great antimicrobial effectiveness of

\section{REFERENCES}

Alkawareek, M. Y., Algwari, Q. T., Laverty, G., Gorman, S. P., Graham, W. G., O'Connell, D., et al. (2012). Eradication of Pseudomonas aeruginosa biofilms by atmospheric pressure non-thermal plasma. PLOS ONE 7:, e44289. doi: 10.1371/journal.pone.0044289

Alvarez, I., Raso, J., Palop, A., and Sala, F.J. (2000). Influence of different factors on the inactivation of Salmonella senftenberg by pulsed electric fields. Int. J. Food Microbiol. 55, 143-146. doi: 10.1016/S0168-1605 (00)00173-2
NTAP in comparison with other technologies that affect a single component or cellular structure. The relative contribution of each individual damage to the total lethal effect of NTAP is unknown yet, since, on the one hand, the composition of plasmas may be very different depending on the conditions of production and, on the other hand, the magnitude of the damage could be in turn dependent on the type of microorganism and the time of treatment (Muranyi et al., 2010; Fröhling et al., 2012b; Tseng et al., 2012; Han et al., 2013, 2016).

Inadequate reporting of experimental methodologies may hinder independent verification and validation of results among different laboratories and equipment units. It is therefore advisable to establish a set of recommended guidelines for conducting and reporting NTAP experiments which would help improve the reliability of future experimental data, thus facilitating process optimization for industrial implementation. Some suggestions on this regard are provided in Table 3.

However, the industrial implementation of NTAP with these aims still requires substantial research efforts, which should be especially focused at (i) assessing the impact that NTAP shows on the nutritional and sensory quality of treated foods in order to facilitate the design of preservation regimes capable of inhibiting pathogenic and spoilage microorganisms while maintaining food quality attributes; (ii) identifying the plasma components and reactive species responsible for the antimicrobial activity of NTAP, which will allow a better selection of processing conditions; (iii) confirming the lack of toxicity of the chemical species generated during NTAP treatments; (iv) developing combined preservation treatments, within a hurdles technology concept, where other inactivation approaches showing a synergic effect when applied together with NTAP will be used; (v) and designing fit-for-purpose equipment susceptible to be easily adopted in a processing line, being compact, energetically efficient, and cost-effective.

\section{AUTHOR CONTRIBUTIONS}

All authors listed have made a substantial, direct and intellectual contribution to the work, and approved it for publication.

\section{ACKNOWLEDGMENTS}

The authors would like to acknowledge the financial support from Junta de Castilla y León (LE077G18) and Ministerio de Ecnonomía y Competitividad (AGL2017-82779-C2). 
Salmonella Typhimurium in response to growth conditions and their effect on heat resistance. Int. J. Food Microbiol. 123, 212-219. doi: 10.1016/j.ijfoodmicro.2008.01.015

Baier, M., Ehlbeck, J., Knorr, D., Herppich, W. B., and Schlüter, O. (2015). Impact of plasma processed air (PPA) on quality parameters of fresh produce. Postharvest Biol. Tec. 100, 120-126. doi: 10.1016/j.postharvbio.2014.09.015

Baier, M., Görgen, M., Ehlbeck, J., Knorr, D., Herppich, W. B., and Schlüte, O. (2014). Non-thermal atmospheric pressure plasma: screening for gentle process conditions and antibacterial efficiency on perishable fresh produce. Innov.Food Sci. Emerg. Technol. 22, 147-157. doi: 10.1016/j.ifset.2014.01.011

Bazaka, K., Jacob, M. V., Chrzanowski, W., and Ostrikov, K. (2015). Antibacterial surfaces: Natural agents, mechanisms of action, and plasma surface modification. RSC Adv. 5, 48739-48759. doi: 10.1039/C4RA17244B

Berardinelli, A., Pasquali, F., Cevoli, C., Trevisani, M., Ragni, L., Mancusi, R., et al. (2016). Sanitisation of fresh-cut celery and radicchio by gas plasma treatments in water medium. Postharvest Biol. Tec. 111, 297-304. doi: 10.1016/j.postharvbio.2015.09.026

Bermúdez-Aguirre, D., Wemlinger, E., Pedrow, P., Barbosa-Cánovas, G., and Garcia-Perez, M. (2013). Effect of atmospheric pressure cold plasma (APCP) on the inactivation of Escherichia coli in fresh produce. Food Control 34, 149--157. doi: 10.1016/j.foodcont.2013.04.022

Boudam, M. K., Moisan, M., Saoudi, B., Popovici, C., Gherardi, N., and Massines, F. (2006). Bacterial spore inactivation by atmospheric-pressure plasmas in the presence or absence of UV photons as obtained with the same gas mixture. J. Phys. D Appl. Phys. 39, 3494-3507. doi: 10.1088/0022-3727/39/16/S07

Brandes, N., Schmitt, S., and Jakob, U. (2009). Thiol-based redox switches in eukaryotic proteins. Antioxid. Redox Signal. 11, 997-1014. doi: $10.1089 /$ ars.2008.2285

Burts, M. L., Alexeff, I., Meek, E. T., and McCullers, J. A. (2009). Use of atmospheric non-thermal plasma as a disinfectant for objects contaminated with methicillin-resistant Staphylococcus aureus. Am. J. Infect. Control 7, 729-733. doi: 10.1016/j.ajic.2009.03.010

Butscher, D., Zimmermann, D., Schuppler, M., and von Rohr, P. R. (2016). Plasma inactivation of bacterial endospores on wheat grains and polymeric model substrates in a dielectric barrier discharge. Food Control 60, 636-645. doi: 10.1016/j.foodcont.2015.09.003

Calvo, T., Alvarez-Ordóñez, A., Prieto, M., Bernardo, A., and López, M. (2017). Stress adaptation has a minor impact on the effectivity of Non-Thermal Atmospheric Plasma (NTAP) against Salmonella spp. Food Res. Int. 102, 519-525. doi: 10.1016/j.foodres.2017.09.035

Calvo, T., Álvarez-Ordóñez, A., Prieto, M., González-Raurich, M., and López, M. (2016). Influence of processing parameters and stress adaptation on the inactivation of Listeria monocytogenes by Non-Thermal Atmospheric Plasma (NTAP). Food Res. Int. 89, 631-637. doi: 10.1016/j.foodres. 2016.09.014

Chen, C. W., Lee, H. M., and Chang, M. B. (2009). Influence of $\mathrm{pH}$ on inactivation of aquatic microorganisms with a gas-liquid pulse electrical discharge. $J$. Electrostat. 67, 703-708. doi: 10.1016/j.elstat.2009.03.008

Choi, S., Puligundla, P., and Mok, C. (2016). Corona discharge plasma jet for inactivation of Escherichia coli $\mathrm{O} 157: \mathrm{H} 7$ and Listeria monocytogenes on inoculated pork and its impact on meat quality attributes. Ann. Microbiol. 66, 685-694. doi: 10.1007/s13213-015-1147-5

Choi, S., Puligundla, P., and Mok, C. (2017). Effect of corona discharge plasma on microbial decontamination of dried squid shreds including physicochemical and sensory evaluation. LWT Food Sci. Technol. 75, 323-328. doi: 10.1016/j.lwt.2016.08.063

Colagar, A. H., Sohbatzadeh, F., Mirzanejhad, S., and Omran, A. V. (2010). Sterilization of Streptococcus pyogenes by afterglow dielectric barrier discharge using $\mathrm{O}_{2}$ and $\mathrm{CO}_{2}$ working gases. Biochem. Eng. J. 51, 189-193. doi: 10.1016/j.bej.2010.06.017

Cui, H., Ma, C., Li, C., and Lin, L. (2016b). Enhancing the antibacterial activity of thyme oil against Salmonella on eggshell by plasma-assisted process. Food Control 70, 183-190. doi: 10.1016/j.foodcont.2016.05.056

Cui, H., Ma, C., and Lin, L. (2016a). Synergetic antibacterial efficacy of cold nitrogen plasma and clove oil against Escherichia coli O157:H7 biofilms on lettuce. Food Control 66, 8-16. doi: 10.1016/j.foodcont.2016.01.035

Daeschlein, G., Scholz, S., Ahmed, R., von Woedtke, T., Haase, H., Niggemeier, M., et al. (2012). Skin decontamination by low-temperature atmospheric pressure plasma jet and dielectric barrier discharge plasma. J. Hosp. Infect. 81, 177-183. doi: 10.1016/j.jhin.2012.02.012

Dasan, B. G., Mutlu, M., and Boyaci, I. H. (2016). Decontamination of Aspergillus flavus and Aspergillus parasiticus spores on hazelnuts via atmospheric pressure fluidized bed plasma reactor. Int. J. Food Microbiol. 216, 50-59. doi: 10.1016/j.ijfoodmicro.2015.09.006

del Rio, D., Stewart, A., and Pellegrini, N. (2005). A review of recent studies on malondialdehyde as toxic molecule and biological marker of oxidative stress. Nutr. Metab. Cardiovasc. Dis. 15, 316-328. doi: 10.1016/j.numecd.2005.05.003

Deng, S., Ruan, R., Mok, C. K., Huang, G., Lin, S., and Chen, P. (2007). Inactivation of Escherichia coli on almonds using nonthermal plasma. J. Food Sci. 72, 62-66. doi: $10.1111 /$ j.1750-3841.2007.00275.x

Deng, X. T., Shi, J. J., and Kong, M. G. (2006). Physical mechanisms of inactivation of Bacillus subtilis spores using cold atmospheric plasmas. IEEE Trans. Plasma Sci. 34, 1310-13161310e1316. doi: 10.1109/TPS.2006.877739

Dirks, B. P., Dobrynin, D., Fridman, G., Mukhin, Y., Fridman, A., and Quinlan, J. J. (2012). Treatment of raw poultry with nonthermal dielectric barrier discharge plasma to reduce Campylobacter jejuni and Salmonella enterica. J. Food Prot. 75, 22-28. doi: 10.4315/0362-028X.JFP-11-153

Dobrynin, D., Fridman, G., Friedman, G., and Fridman, A. (2009). Physical and biological mechanisms of direct plasma interaction with living tissue. New J. Phys. 11:, 115020. doi: 10.1088/1367-2630/11/11/115020

Dobrynin, D., Friedman, G., Fridman, A., and Starikovskiy, A. (2011). Inactivation of bacteria using de corona discharge: role of ions and humidity. New J. Phys. 13:, 103033. doi: 10.1088/1367-2630/13/10/103033

Edelblute, C. M., Malik, M. A., and Heller, L. C. (2015). Surface-dependent inactivation of model microorganisms with shielded sliding plasma discharges and applied air flow. Bioelectrochemistry 103, 22-27. doi: 10.1016/j.bioelechem.2014.08.013

Ercan, U. K., Smith, J., Ji, H. F., Brooks, A. D., and Josh, S. G. (2016). Chemical changes in nonthermal plasma-treated $\mathrm{N}$-acetylcysteine (NAC) solution and their contribution to bacterial inactivation. Sci. Rep. 6, 20365; doi: $10.1038 /$ srep 20365

Ercan, U. K., Wang, H., Ji, H. F., Fridman, G., Brooks, A. D., and Joshi, S. G. (2013). Nonequilibrium plasma-activated antimicrobial solutions are broad-spectrum and retain their efficacies for extended period of time. Plasma Process. Polym. 10, 544-555. doi: 10.1002/ppap.201200104

Eto, H., Ono, Y., Ogino, A., and Nagatsu, M. (2008). Low-temperature sterilization of wrapped materials using flexible sheet-type dielectric barrier discharge. Appl. Phys. Lett. 93, 221502. doi: 10.1063/1.3039808

Fang, F. C. (2004). Antimicrobial reactive oxygen and nitrogen species: concepts and controversies. Nat. Rev. Microbiol. 2, 820-832. doi: 10.1038/nrmicro1004

Fernández, A., Noriega, E., and Thompson, A. (2013). Inactivation of Salmonella enterica serovar Typhimurium on fresh produce by cold atmospheric gas plasma technology. Food Microbiol. 33, 24-29. doi: 10.1016/j.fm.2012.08.007

Fernández, A., Shearer, N., Wilson, D. R., and Thompson, A. (2012). Effect of microbial loading on the efficiency of cold atmospheric gas plasma inactivation of Salmonella enterica serovar Typhimurium. Int. J. Food Microbiol. 152, 175-180. doi: 10.1016/j.ijfoodmicro.2011.02.038

Flynn, P. B., Higginbotham, S., Alshraiedeh, N. H., Gorman, S. P., Graham, W. G., and Gilmore, B. F. (2015). Bactericidal efficacy of atmospheric pressure nonthermal plasma (APNTP) against the ESKAPE pathogens. Int. J. Antimicrob. Agents 46, 101-107. doi: 10.1016/j.ijantimicag.2015.02.026

Fröhling, A., Baier, M. J., Ehlbeck, J., Knorr, D., and Schlüter, O. (2012b). Atmospheric pressure plasma treatment of Listeria innocua and Escherichia coli at polysaccharide surfaces: inactivation kinetics and flow cytometric characterization. Innov. Food Sci. Emerg. Technol. 13, 142-150. doi: $10.1016 /$ j.ifset.2011.11.002

Fröhling, A., Durek, J., Schnabel, U., Ehlbeck, J., Bolling, J., and Schlüter, O. (2012a). Indirect plasma treatment of fresh pork: decontamination efficiency and effects on quality attributes. Innov. Food Sci. Emerg. Technol. 16, 381-390. doi: 10.1016/j.ifset.2012.09.001

Gabriel, A. A., Aba, R. P. M., Tayamora, D. J. L., Colambo, J. C. R., Siringan, M. A. T., Rosario, L. M. D., et al. (2016a). Reference organism selection for microwave atmospheric pressure plasma jet treatment of young coconut liquid endosperm. Food Control 69, 74-82. doi: 10.1016/j.foodcont.2016.04.034

Gabriel, A. A., Clarisse, M. C., Ugay, F., Siringan, M. A. T., Rosario, L. M. D., Tumlos, R. B., et al. (2016b). Atmospheric pressure plasma jet inactivation of 
Pseudomonas aeruginosa biofilms on stainless steel surfaces. Innov. Food Sci. Emerg. Technol. 36, 311-319. doi: 10.1016/j.ifset.2016.07.015

Galvin, S., Cahill, O., O'Connor, N., Cafolla, A. A., Daniels, S., and Humphreys, H. (2013). The antimicrobial effects of helium and helium-air plasma on Staphylococcus aureus and Clostridium difficile. Lett. Appl. Microbiol. 57, 83-90. doi: 10.1111/lam.1209

Gweon, B., Kim, D. B., Moon, S. Y., and Choe, W. (2009). Escherichia coli deactivation study controlling the atmospheric pressure plasma discharge conditions. Curr. Appl. Phys. 9, 625-628. doi: 10.1016/j.cap.2008.06.001

Han, L., Patil, S., Boehm, D., Milosavljevic, V., Cullen, P. J., and Bourke, P. (2016). Mechanism of inactivation by high voltage atmospheric cold plasma differs between Escherichia coli and Staphylococcus aureus. Appl. Environ. Microbiol. 82, 450-458. doi: 10.1128/AEM.02660-15

Han, L., Patil, S., Keener, K. M., Cullen, P. J., and Bourke, P. (2013). Bacterial inactivation by high-voltage atmospheric cold plasma: influence of process parameters and effects on cell leakage and DNA. J. Appl. Microbiol. 116, 784-794. doi: 10.1111/jam.12426

Hao, X., Mattson, A. M., Edelblute, C. M., Malik, M. A., Heller, L. C., and Kolb, J. F. (2014). Nitric oxide generation with an air operated non-thermal plasma jet and associated microbial inactivation mechanisms. Plasma Process. Polym. 11, 1044-1056. doi: 10.1002/ppap.201300187

Henriques, A. O., and Moran, C. P. Jr. (2007). Structure, assembly, and functions of the spore surface layers. Annu. Rev. Microbiol. 61, 555-588. doi: 10.1146/annurev.micro.61.080706.093224

Hong, Y. F., Kang, J. G., Lee, H. Y., Uhm, H. S., Moon, E., and Park, Y. H. (2009). Sterilization effect of atmospheric plasma on Escherichia coli and Bacillus subtilis endospores. Lett. Appl. Microbiol. 48, 33-37. doi: 10.1111/j.1472-765X.2008.02480.x

Hosseinzadeh Colagar, A., Memariani, H., Sohbatzadeh, F., and Valinataj Omran, A. (2013). Nonthermal atmospheric argón plasma jet effects on Escherichia coli biomacromolecules. App.l Biochem. Biotechnol. 171, 1617-1629. doi: 10.1007/s12010-013-0430-9

Issa-Zacharia, A., Kamitani, Y., Muhimbula, H., and Iwasaki, K. (2010). Antimicrobial effect of slightly acidic electrolyzed water for inactivation of Salmonella spp. and Escherichia coli on fresh strawberries (Fragaria L.). Afr. J. Microbiol. Res. 4, 2174-2180.

Jahid, I. K., Han, N., and Ha, S. D. (2014). Inactivation kinetics of cold oxygen plasma depend on incubation conditions of Aeromonas hydrophila biofilm on lettuce. Food Res. Int. 55, 181-189. doi: 10.1016/j.foodres.2013.11.005

Jayasena, D. D., Kim, H. J., Yong, H. I., Park, S., Kim, K., Choe, W., et al. (2015). Flexible thin-layer dielectric barrier discharge plasma treatment of pork butt and beef loin: Effects on pathogen inactivation and meat-quality attributes. Food Microbiol. 46, 51-57. doi: 10.1016/j.fm.2014.07.009

Joshi, S. G., Cooper, M., Yost, A., Paff, M., Ercan, U. K., Fridman, G., et al. (2011). Nonthermal dielectric-barrier discharge plasma-induced inactivation involves oxidative DNA damage and membrane lipid peroxidation in Escherichia coli. Antimicrob. Agents Chemother. 55, 1053-1062. doi: 10.1128/AAC.01002-10

Jung, H., Kim, D. B., Gweon, B., Moon, S. Y., and Choe, W. (2010). Enhanced inactivation of bacterial spores by atmospheric pressure plasma with catalyst $\mathrm{TiO}_{2}$. Appl. Catal. B-Environ. 93, 212-216. doi: 10.1016/j.apcatb.2009.09.031

Jung, S., Kim, H. J., Park, S., In Yong, H., Choe, J. H., Jeon, H. J., et al. (2015). The use of atmospheric pressure plasma-treated water as a source of nitrite for emulsion-type sausage. Meat Sci. 108, 132-137. doi: 10.1016/j.meatsci.2015.06.009

Kamgang-Youbi, G., Herry, J. M., Brisset, J. L., Bellon-Fontaine, M. N., Doubla, A., and Naitali, M. (2008). Impact on disinfection efficiency of cell load and of planktonic/adherent/detached state: case of Hafnia alvei inactivation by plasma activated water. Appl. Microbiol. Biotechnol. 81, 449-457. doi: 10.1007/s00253-008-1641-9

Kamgang-Youbi, G., Herry, J. M., Meylheuc, T., Brisset, J. L., Bellon-Fontaine, M. N., Doubla, A., et al. (2009). Microbial inactivation using plasma-activated wáter obtained by gliding electric discharges. Lett. Appl. Microbiol. 48, 13-18. doi: 10.1111/j.1472-765X.2008.02476.x

Kim, B., Yun, H., Jung, S., Jung, Y., Jung, H., Choe, W., et al. (2011). Effect of atmospheric pressure plasma on inactivation of pathogens inoculated onto bacon using two different gas compositions. Food Microbiol. 28, 9-13. doi: $10.1016 /$ j.fm.2010.07.022
Kim, H. J., Yong, H. I., Park, S., Choe, W., and Jo, C. (2013). Effects of dielectric barrier discharge plasma on pathogen inactivation and the physicochemical and sensory characteristics of pork loin. Curr. Appl. Phys. 13, 1420-1425. doi: 10.1016/j.cap.2013.04.021

Kim, J. S., Lee, E. J., Choi, E. H., and Kim, Y. J. (2014). Inactivation of Staphylococcus aureus on the beef jerky by radio-frequency atmospheric pressure plasma discharge treatment. Innov. Food Sci. Emerg. Technol. 22, 124-130. doi: 10.1016/j.ifset.2013.12.012

Klämpfl, T. G., Isbary, G., Shimizu, T., Li, Y. F., Zimmermann, J. L., Stolz, W. et al. (2012). Cold atmospheric air plasma sterilization against spores and other microorganisms of clinical interest. Appl. Environ. Microbiol. 78, 5077-5082. doi: 10.1128/AEM.00583-12

Kodama, S., Thawatchaipracha, B., and Sekiguchi, H. (2014). Enhancement of essential oil extraction for steam distillation by DBD surface treatment. Plasma Process. Polym. 11, 126-132. doi: 10.1002/ppap.201300047

Lackmann, J. W., and Bandow, J. E. (2014). Inactivation of microbes and macromolecules by atmospheric-pressure plasma jets. Appl. Microbiol. Biotechnol. 98, 6205-6213. doi: 10.1007/s00253-014-5781-9

Lackmann, J. W., Schneider, S., Edengeiser, E., Jarzina, F., Brinckmann, S., Steinborn, E., et al. (2013). Photons and particles emitted from cold atmospheric-pressure plasma inactivate bacteria and biomolecules independently and synergistically. J. Royal Soc. Interface 10:, 20130591. doi: 10.1098/rsif.2013.0591

Lacombe, A., Niemira, B. A., Gurtler, J. B., Fan, X., Sites, J., Boyd, G., et al. (2015). Atmospheric cold plasma inactivation of aerobic microorganisms on blueberries and effects on quality attributes. Food Microbiol. 46, 479-484. doi: 10.1016/j.fm.2014.09.010

Lai, A. C. K., Cheung, A. C. T., Wong, M. M. L., and Li, W. S. (2016). Evaluation of cold plasma inactivation efficacy against different airborne bacteria in ventilation duct flow. Build. Environ. 98, 39-46. doi: 10.1016/j.buildenv.2015.12.005

Laroussi, M., and Leipold, F. (2004). Evaluation of the roles of reactive species, heat, and UV radiation in the inactivation of bacterial cells by air plasmas at atmospheric pressure. Int.ernational J.ournal of Mass Spectrometr.y 233, 81-86. doi: 10.1016/j.ijms.2003.11.016

Laroussi, M., Mendis, D. A., and Rosenberg, M. (2003). Plasma interaction with microbes. New J. Phys. 5, 41.1-41.10. doi: 10.1088/1367-2630/5/1/341

Lee, H. J., Jung, H., Choe, W., Ham, J. S., Lee, J. H., and Jo, C. (2011). Inactivation of Listeria monocytogenes on agar and processed meat surfaces by atmospheric pressure plasma jets. Food Microbiol. 28, 1468-1471. doi: $10.1016 /$ j.fm.2011.08.002

Lee, H. J., Jung, S., Jung Park, S., Choe, W., Ham, J. S., and Jo, C. (2012a). Evaluation of dielectric barrier discharge plasma system for inactivating pathogens on cheese slices. J. Anim. Sci. Technol. 54, 191-198. doi: 10.5187/JAST.2012.54.3.191

Lee, H. J., Song, H. P., Jung, H. S., Choe, W. H., Ham, J. S., Lee, J. H., et al. (2012b). Effect of atmospheric pressure plasma jet on inactivation of Listeria monocytogenes, quality, and genotoxicity of cooked egg white and yolk. Korean J. Food Sci. Anim. Resour. 32, 561-570. doi: 10.5851/kosfa.2012. 32.5.561

Lee, K., Paek, K. H., Ju, W. T., and Lee, Y. (2006). Sterilization of bacteria, yeast, and bacterial endospores by atmospheric-pressure cold plasma using helium and oxygen. J Microbiol. 44, 269-275.

Leipold, F., Kusano, Y., Hansen, F., and Jacobsen, T. (2010). Decontamination of a rotating cutting tool during operation by means of atmospheric pressure plasmas. Food Control 21, 1194-1198. doi: 10.1016/j.foodcont.2010. 02.006

Lemire, J. A., Harrison, J. J., and Turner, R. J. (2013). Antimicrobial activity of metals: mechanisms, molecular targets and applications. Nat. Rev. Microbiol. 11, 371-384. doi: $10.1038 /$ nrmicro3028

Liao, X., Li, J., Muhammad, A. I., Suo, Y., Chen, S., Ye, X., et al. (2018). Application of a dielectric barrier discharge atmospheric cold plasma (DbdAcp) for Escherichia coli inactivation in apple juice. J. Food Sci. 83, 401-408. doi: 10.1111/1750-3841.14045

Lieberman, M. A., and Lichtenberg, A. J. (2005). Principles of Plasma Discharges and Materials Processing. Hoboken, NJ: Wiley-Interscience. doi: $10.1002 / 0471724254$ 
Lim, Y. B., Park, S., Kim, H. R., Yong, H. I., Kim, S. H., and Lee, H. J. (2015). Plasma Treatment Process for Processed Meat and Plasma Treatment Apparatus for Processed Meat. Korea Patent Submission Number 10-20150029641. Submission date at March 3, 2015.

Liu, F., Sun, P., Bai, N., Tian, Y., Zhou, H., Wei, S., et al. (2010), Inactivation of bacteria in an aqueous environment by a direct-current, coldatmospheric-pressure air plasma microjet., Plasma Process. Polym. 7, 231-236. doi: 10.1002/ppap.200900070

Liu, H., Chen, J., Yang, L., and Zhou, Y. (2008). Long-distance oxygen plasma sterilization: effects and mechanisms. Appl. Surf. Sci. 254, 1815-1821. doi: 10.1016/j.apsusc.2007.07.152

Liu, X. H., Hong, F., Guo, Y., Zhang, J., and Shi, J. J. (2013). Sterilization of Staphylococcus aureus by an atmospheric non-thermal plasma jet. Plasma Sci. Technol. 15, 339-342. doi: 10.1088/1009-0630/15/5/09

Ma, R., Wang, G., Tian, Y., Wang, K., Zhang, J., and Fang, J. (2015). Nonthermal plasma-activated water inactivation of food-borne pathogen on fresh produce. J. Hazard. Mater 300, 643-651. doi: 10.1016/j.jhazmat.2015. 07.061

Mañas, P., and Mackey, B. M. (2004). Morphological and physiological changes induced by high hydrostatic pressure in exponential- and stationary-phase cells of Escherichia coli: relationship with cell death. App. Environ. Microbiol. 70, 1545-1554. doi: 10.1128/AEM.70.3.1545-1554.2004

Marsili, L., Espie, S., Anderson, J. G., and MacGregor, S. J. (2002). Plasma inactivation of food-related microorganisms in liquids. Radiat. Phys Chem. 65, 507-513. doi: 10.1016/S0969-806X(02)00367-5

Martínez, S., López, M., and Bernardo, A. (2003). Thermal inactivation of Enterococcus faecium: effect of growth temperature and physiological state of microbial cells. Lett. Appl. Microbiol. 37, 475-481. doi: 10.1046/j.1472-765X.2003.01431.x

Menashi, W. P. (1968). Treatment of Surfaces. US Patent 3383163.

Miao, H., and Jierong, C. (2009). Inactivation of Escherichia coli and properties of medical poly(vinyl chloride) in remote-oxygen plasma. Appl. Surf. Sci. 255, 5690-5697. doi: 10.1016/j.apsusc.2008.12.056

Miao, H., and Yun, G. (2011). The sterilization of Escherichia coli by dielectricbarrier discharge plasma at atmospheric pressure. Appl. Surf. Sci. 257, 7065-7070. doi: 10.1016/j.apsusc.2011.03.014

Misra, N. N., Kaur, S., Tiwari, B. K., Kaur, A., Singh, N., and Cullen, P. J. (2015). Atmospheric pressure cold plasma (ACP) treatment of wheat flour. Food Hydrocoll. 44, 115-121. doi: 10.1016/j.foodhyd.2014. 08.019

Misra, N. N., Sullivan, C., Pankaj, S. K., Alvarez-Jubete, L., Cama, R., Jacoby, F., et al. (2014). Enhancement of oil spreadability of biscuit surface by nonthermal barrier discharge plasma. Innov. Food Sci. Emerg. Technol. 26, 456-461. doi: 10.1016/j.ifset.2014.10.001

Mols, M., Mastwijk, H., Nierop Groot, M., and Abee, T. (2013). Physiological and transcriptional response of Bacillus cereus treated with low-temperature nitrogen gas plasma. J. Appl. Microbiol. 115 , 689-702. doi: 10.1111/ jam. 12278

Montenegro, J., Ruan, R., Ma, H., and Chen, P. (2002). Inactivation of E. coli O157:H7 using a pulsed nonthermal plasma system. J. Food Sci. 67, 646-648. doi: 10.1111/j.1365-2621.2002.tb10653.x

Muranyi, P., Wunderlich, J., and Heise, M. (2007). Sterilization efficiency of a cascaded dielectric barrier discharge. J. Appl. Microbiol. 103, 1535-1544. doi: 10.1111/j.1365-2672.2007.03385.x

Muranyi, P., Wunderlich, J., and Heise, M. (2008). Influence of relative gas humidity on the inactivation efficiency of a low temperature gas plasma. J. Appl. Microbiol. 104, 1659-1666. doi: 10.1111/j.1365-2672.2007.03691.x

Muranyi, P., Wunderlich, J., and Langowski, H. C. (2010). Modification of bacterial structures by a low-temperature gas plasma and influence on packaging material. J. Appl. Microbiol. 109, 1875-1885. doi: 10.1111/j.1365-2672.2010.04815.x

Naïtali, M., Kamgang-Youbi, G., Herry, J. M., Bellon-Fontaine, M. N., and Brisset, J. L. (2010). Combined effects of long- living chemical species during microbial inactivation using atmospheric plasma-treated water. Appl. Environ. Microbiol. 76, 7662-7664. doi: 10.1128/AEM.01615-10

Niemira, B. A. (2012). Cold plasma reduction of Salmonella and Escherichia coli O157:H7 on almonds using ambient pressure gases. J. Food Sci. 77, 171-175. doi: $10.1111 /$ j.1750-3841.2011.02594.x
Nishime, T. M. C., Borges, A. C., Koga-Ito, C. Y., Machida, M., Hein, L. R. O., and Kostov, K. G. (2017). Non-thermal atmospheric pressure plasma jet applied to inactivation of different microorganisms. Surf. Coat. Technol. 312, 19-24. doi: 10.1016/j.surfcoat.2016.07.076

Noriega, E., Shama, G., Laca, A., Díaz, M., and Kong, M. G. (2011). Cold atmospheric gas plasma disinfection of chicken meat and chicken skin contaminated with Listeria innocua. Food Microbiol. 28, 1293-1300. doi: 10.1016/j.fm.2011.05.007

Oehmigen, K., Hähnel, M., Brandenburg, R., Wilke, C., Weltmann, K., and von Woedtke, T. (2010). The role of acidification for antimicrobial activity of atmospheric pressure plasma in liquids. Plasma Process. Polym. 7, 250-257 doi: 10.1002/ppap.200900077

Pan, Y., Breidt, F., and Kathariou, S. (2006). Resistance of Listeria monocytogenes bio- film to sanitizing agents in a simulated food processing environment. Appl. Environ. Microbiol. 72, 7711-7717. doi: 10.1128/AEM.01065-06

Patil, S., Moiseev, T., Misra, N. N., Cullen, P. J., Mosnier, J. P., Keener K. M., et al. (2014). Influence of high voltage atmospheric cold plasma process parameters and role of relative humidity on inactivation of Bacillus atrophaeus spores inside a sealed package. J. Hosp. Infect. 88, 162-169. doi: 10.1016/j.jhin.2014.08.009

Perni, S., Shama, G., Hobman, J. L., Lund, P. A., Kershaw,; C. J., HidalgoArroyo, G. A., et al. (2007). Probing bactericidal mechanisms induced by cold atmospheric plasmas with Escherichia coli mutants. Appl. Phys. Lett. 90: 73902. doi: 10.1063/1.2458162

Pomposiello, P. J., and Demple, B. (2002). Global adjustment of microbial physiology during free radical stress. Adv. Microb. Physiol. 46, 319-341. doi: 10.1016/S0065-2911(02)46007-9

Puligundla, P., Kim, J. W., and Mok, C. (2017). Effect of corona discharge plasma jet treatment on decontamination and sprouting of rapeseed (Brassica napus $L$.) seeds. Food Control 71, 376-382. doi: 10.1016/j.foodcont.2016.07.021

Purevdorj, D., Igura, N., Shimoda, M., Ariyada, O., and Hayakawa, I. (2001). Kinetics of inactivation of Bacillus spores using low temperature argon plasma at different microwave power densities. Acta Biotechnol. 21, 333-342. doi: 10.1002/1521-3846(200111)21:4<333::AID-ABIO333>3.0.CO;2-6

Ragni, L., Berardinelli, A., Vannini, L., Montanari, C., Sirri, F., Guerzoni, M. E., et al. (2010). Non-thermal atmospheric gas plasma device for surface decontamination of shell eggs. J. Food Eng. 100, 125-132. doi: 10.1016/j.jfoodeng.2010.03.036

Reineke, K., Langer, K., Hertwig, C., Ehlbeck, J., and Schlüter, O. (2015). The impact of different process gas compositions on the inactivation effect of an atmospheric pressure plasma jet on Bacillus spores. Innov. Food Sci. Emerg. Technol. 30, 112-118 doi: 10.1016/j.ifset.2015.03.019

Rød, S. K., Hansen, F., Leipold, F., and Knøchel, S. (2012). Cold atmospheric pressure plasma treatment of ready-to-eat meat: inactivation of Listeria innocua and changes in product quality. Food Microbiol. 30, 233-238. doi: $10.1016 / \mathrm{j} . \mathrm{fm} .2011 .12 .018$

Rowan, N. J., Espie, S., Harrower, J., Anderson, J. G., Marsili, L., and MacGregor, S. J. (2007). Pulsed-plasma gas discharge inactivation of microbial pathogens in chilled poultry wash water. J. Food Prot. 70, 2805-2810. doi: 10.4315/0362-028X-70.12.2805

Ryu, Y. H., Kim, Y. H., Lee, J. Y., Shim, G. B., Uhm, H. S., Park, G., et al. (2013). Effects of background fluid on the efficiency of inactivating yeast with non-thermal atmospheric pressure plasma. PLoS ONE 8, e66231 doi: 10.1371/journal.pone.0066231

Sharma, A., Collins, G., and Pruden, A. (2009). Differential gene expression in Escherichia coli following exposure to nonthermal atmospheric pressure plasma. J. Appl. Microbiol. 107, 1440-1449. doi: 10.1111/j.1365-2672.2009.04323.x

Shi, X., and Zhu, X. (2009). Biofilm formation and food safety in food industries. Trends Food Sci Technol. 20, 407-413. doi: 10.1016/j.tifs.2009.01.054

Shi, X. M., Zhang, G. J., Wu, X. L., Li, Y. X., Ma, Y., and Shao, X. J. (2011). Effect of low-temperature plasma on microorganism inactivation and quality of freshly squeezed orange juice. IEEE T. Plasma Sci. 39, 1591-1597. doi: 10.1109/TPS.2011.2142012

Song, H. P., Kim, B., Choe, J. M., Jung, S., Moon, S. Y., Choe, W., et al. (2009). Evaluation of atmospheric pressure plasma to improve the safety of slice cheese and ham inoculated by 3-strain cocktail Listeria monocytogenes. Food Microbiol. 26, 432-436. doi: 10.1016/j.fm.2009.02.010 
Sun, P., Wu, H. Y., Bai, N., Zhou, H. X., Wang, R. X., Feng, H. Q., et al. (2012). Inactivation of Bacillus subtilis spores in water by a direct-current, cold atmospheric-pressure air plasma microjet. Plasma Process Polym. 9, 157-164. doi: 10.1002/ppap.201100041

Sun, S., Anderson, N. M., and Keller, S. (2014). Atmospheric pressure plasma treatment of black peppercorns inoculated with Salmonella and held under controlled storage. J. Food Sci. 79, 2441-2446. doi: 10.1111/1750-38 41.12696

Surowsky, B., Fischer, A., Schlueter, O., and Knorr, D. (2013). Cold plasma effects on enzyme activity in a model food system. Innov. Food Sci. Emerg. Technol. 19, 146-152. doi: 10.1016/j.ifset.2013.04.002

Surowsky, B., Fröhling, A., Gottschalk, N., Schlüter, O., and Knorr, D. (2014). Impact of cold plasma on Citrobacter freundii in apple juice: inactivation kinetics and mechanisms. Int. J. Food Microbiol. 174, 63-71. doi: 10.1016/j.ijfoodmicro.2013.12.031

Takamatsu, T., Uehara, K., Sasaki, Y., Hidekazu, M., Matsumura, Y., Iwasawa, A., et al. (2015). Microbial Inactivation in the liquid phase induced by multigas plasma jet. PLoS ONE 10:, e0132381. doi: 10.1371/journal.pone.0132381

Thirumdas, R., Deshmukh, R. R., and Annapure, U. S. (2015). Effect of low temperature plasma processing on physicochemical properties and cooking quality of basmati rice. Innov. Food Sci. Emerg. Technol. 31, 83-90. doi: 10.1016/j.ifset.2015.08.003

Tian, Y., Ma, R., Zhang, Q., Feng, H., Liang, Y., Zhang, J., et al. (2015). Assessment of the physicochemical properties and biological effects of water activated by non-thermal plasma above and beneath the water surface. Plasma Process. Polym. 12, 439-449. doi: 10.1002/ppap.201400082

Tseng, S., Abramzon, N., Jackson, J. O., and Lin, W.-J. (2012). Gas discharge plasmas are effective in inactivating Bacillus and Clostridium spores. Appl. Microbiol. Biotechnol. 93, 2563-2570. doi: 10.1007/s00253-011-3661-0

van Bokhorst-van de Veen, H., Xie, H., Esveld, E., Abee, T., Mastwijk, H., and Nierop Groot, M. (2015). Inactivation of chemical and heat-resistant spores of Bacillus and Geobacillus by nitrogen cold atmospheric plasma evokes distinct changes in morphology and integrity of spores. Food Microbiol. 45, 26-33. doi: 10.1016/j.fm.2014.03.018

Vleugels, M., Shama, G., Deng, X. T., Greenacre, E. J., Brocklehurst, T. F., and Kong, M. G. (2005). Atmospheric plasma inactivation of biofilmforming bacteria for food safety control. IEEE T. Plasma Sci. 33, 824-828. doi: 10.1109/TPS.2005.844524

Wang, R. X., Nian, W. F., Wu, H. Y., Feng, H. Q., Zhang, K., Zhang, J., et al. (2012). Atmospheric-pressure cold plasma treatment of contaminated fresh fruit and vegetable slices: inactivation and physiochemical properties evaluation. Eur. Phys. J. D 66:, 276. doi: 10.1140/epjd/e2012-30053-1

Xu, Y., Tian, Y., Ma, R., Liu, Q., and Zhang, J. (2016). Effect of plasma activated water on the postharvest quality of button mushrooms, Agaricus bisporus. Food Chem. 197, 436-444. doi: 10.1016/j.foodchem.2015.10.144

Yong, H. I., Kim, H. J., Park, S., Alahakoon, A. U., Kim, K., Choe, W., et al. (2015a). Evaluation of pathogen inactivation on sliced cheese induced by encapsulated atmospheric pressure dielectric barrier discharge plasma. Food Microbiol. 46, 46-50. doi: 10.1016/j.fm.2014.07.010
Yong, H. I., Kim, H. J., Park, S., Kim, K., Choe, W., Yoo, S. J., et al. (2015b). Pathogen inactivation and quality changes in sliced cheddar cheese treated using flexible thin-layer dielectric barrier discharge plasma. Food Res. Int. 69, 57-63. doi: 10.1016/j.foodres.2014.12.008

Yong, H. I., Lee, H., Park, S., Park, J., Choe, W., Jung, S., et al. (2017). Flexible thinlayer plasma inactivation of bacteria and mold survival in beef jerky packaging and its effects on the meat's physicochemical properties. Meat Sci. 123, 151-156. doi: 10.1016/j.meatsci.2016.09.016

Yost, A. D., and Joshi, S. G. (2015). Atmospheric nonthermal plasma-treated PBS inactivates Escherichia coli by oxidative DNA damage. PLoS ONE 10:(10): e0139903. doi: 10.1371/journal.pone.0139903

Yu, H., Perni, S., Shi, J. J., Wang, D. Z., Kong, M. G., and Shama, G. (2006). Effects of cell surface loading and phase of growth in cold atmospheric gas plasma inactivation of Escherichia coli K12. J. Appl. Microbiol. 101, 1323-1330. doi: 10.1111/j.1365-2672.2006.03033.x

Yun, H., Kim, B., Jung, S., Kruk, Z. A., Kim, D. B., Choe, W., et al. (2010). Inactivation of Listeria monocytogenes inoculated on disposable plastic tray, aluminum foil, and paper cup by atmospheric pressure plasma. Food Control 21, 1182-1186. doi: 10.1016/j.foodcont.2010.02.002

Zhang, Q., Liang, Y., Feng, H., Ma, R., Tian, Y., Zhang, J., et al. (2013). A study of oxidative stress induced by non-thermal plasma-activated water for bacterial damage. Appl. Phys. Lett. 102, 203701 doi: 10.1063/1.4807133

Ziuzina, D., Boehm, D., Patil, S., Cullen, P. J., and Bourke, P. (2015a). Cold plasma inactivation of bacterial biofilms and reduction of quorum sensing regulated virulence factors. PLOS ONE 10(9), e0138209. doi: 10.1371/journal.pone.0138209

Ziuzina, D., Han, L., Cullen, P. J., and Bourke, P. (2015b). Cold plasma inactivation of internalised bacteria and biofilms for Salmonella enterica serovar Typhimurium, Listeria monocytogenes and Escherichia coli. Int.ernational J. Food Microbiol. 210, 53-61. doi: 10.1016/j.ijfoodmicro.2015.05.019

Ziuzina, D., Patil, S., Bourke, P., Keener, K., and Cullen, P. J. (2013). Atmospheric cold plasma inactivation of Escherichia coli in liquid media inside a sealed package. J. Appl. Microbiol. 114, 778-787. doi: 10.1111/jam.12087

Ziuzina, D., Patil, S., Cullen, P. J., Keener, K. M., and Bourke, P. (2014) Atmospheric cold plasma inactivation of Escherichia coli, Salmonella enterica serovar Typhimurium and Listeria monocytogenes inoculated on fresh produce. Food Microbiol. 42, 109-116. doi: 10.1016/j.fm.2014.02.007

Conflict of Interest Statement: The authors declare that the research was conducted in the absence of any commercial or financial relationships that could be construed as a potential conflict of interest.

Copyright (๔ 2019 López, Calvo, Prieto, Múgica-Vidal, Muro-Fraguas, Alba-Elías and Alvarez-Ordónez. This is an open-access article distributed under the terms of the Creative Commons Attribution License (CC BY). The use, distribution or reproduction in other forums is permitted, provided the original author(s) and the copyright owner(s) are credited and that the original publication in this journal is cited, in accordance with accepted academic practice. No use, distribution or reproduction is permitted which does not comply with these terms. 